\title{
Nickel-Sulfonate Mode of Substrate Binding for Forward and Reverse Reactions of Methyl-SCoM Reductase Suggest a Radical Mechanism Involving Long Range Electron Transfer
}

\author{
Anjali Patwardhan ${ }^{\ddagger}$, Ritimukta Sarangi ${ }^{\S}$, Bojana.Ginovska $^{\$}$, Simone Raugei $^{\S}$, and Stephen W. \\ Ragsdale $^{\ddagger *}$
}

From the ${ }^{\ddagger}$ Department of Biological Chemistry, University of Michigan, Ann Arbor, Michigan 48103, and ${ }^{\S}$ Stanford Synchrotron Radiation Lightsource, SLAC National Accelerator Laboratory, Menlo Park, California 94025 and ${ }^{\$}$ Pacific Northwest National Laboratory, Richland, WA 99354

\section{Running title: Substrate binding via nickel-sulfonate to methyl-SCoM reductase}

${ }^{1}$ To whom correspondence should be addressed: Department of Biological, Chemistry, University of Michigan Medical School, 1150 W. Medical Center Dr., 5301 MSRB III, Ann Arbor, MI USA, 481090606, Tel: 734-615-4621; Fax: 734-763-4581; E-mail: sragsdal@umich.edu

Work in SWR's group was supported by the US Department of Energy (DOE), Office of Science, Basic Energy Sciences (BES) (Grant DE-FG02-08ER15931). The SSRL Structural Molecular Biology Program is supported by the DOE Office of Biological and Environmental Research, and by the National Institutes of Health, National Institute of General Medical Sciences (P30GM133894). Support for SR and BG was provided by DOE, Office of Science, BES, Division of Chemical Sciences, Geosciences, and Biosciences. Pacific Northwest National Laboratory is operated by Battelle for the U.S. DOE.

Keywords: nickel; methane; long-range electron transfer; radical transfer; X-ray absorption; computational chemistry; enzyme mechanisms; enzyme kinetics.

\begin{abstract}
Methyl-coenzyme M reductase (MCR) catalyzes both synthesis and anaerobic oxidation of methane (AOM). Its catalytic site contains $\mathrm{Ni}$ at the core of Cofactor $\mathrm{F}_{430}$. The $\mathrm{Ni}$ ion, in its low-valent $\mathrm{Ni}(\mathrm{I})$ state lights the fuse leading to homolysis of the C-S bond of methyl-coenzyme M (methyl-SCoM) to generate a methyl radical, which abstracts a hydrogen atom from Coenzyme B ( $\mathrm{HSCoB})$ to generate methane and the mixed disulfide CoMSSCoB. Direct reversal of this reaction activates methane to initiate anaerobic methane oxidation. Based on crystal structures, which reveal a Ni-thiol interaction between $\mathrm{Ni}(\mathrm{II})-\mathrm{MCR}$ and inhibitor CoMSH, a Ni(I)-thioether complex with substrate methyl-SCoM has been transposed to canonical MCR mechanisms. Similarly, a Ni(I)disulfide with CoMSSCoB is proposed for the reverse reaction. However, this $\mathrm{Ni}(\mathrm{I})$-sulfur interaction poses a conundrum for the proposed hydrogen atom abstraction reaction because the $>6$ $\AA$ distance between the thiol group of $\mathrm{SCoB}$ and the
\end{abstract}

thiol of SCoM observed in the structures appears too long for such a reaction. Spectroscopic, kinetic, structural and computational studies described here establish that both methyl-SCoM and CoMSSCoB bind to the active $\mathrm{Ni}(\mathrm{I})$ state of MCR through their sulfonate groups, forming a hexacoordinate $\mathrm{Ni}(\mathrm{I})$ N/O complex, not Ni(I)-S. These studies rule out direct $\mathrm{Ni}(\mathrm{I})$-sulfur interactions in both substratebound states. As a solution to the mechanistic conundrum, we propose that both forward and reverse MCR reactions emanate through long-range electron transfer from $\mathrm{Ni}(\mathrm{I})$-sulfonate complexes with methyl-SCoM or CoMSSCoB, respectively.

Methyl-coenzyme M reductase (MCR), one of the few Ni proteins in nature, catalyzes the reaction of methyl-coenzyme $\mathrm{M} \quad\left(\mathrm{CH}_{3}-\mathrm{SCoM}\right)$ with coenzyme B (HSCoB) in methanogenic archaea to form methane and the heterodisulfide, $\mathrm{CoMSSCoB}$ (Eq. 1) (1). MCR also catalyzes the reverse reaction 
in consortia of anaerobic methane oxidizing archaea (ANME) with sulfate, nitrate or Fe(III) reducing bacteria (2). This manuscript describes the relative orientations of the substrates in the forward and reverse reactions of MCR. Spectroscopic, structural and computational studies identify an unexpected and symmetric complex between active $\mathrm{Ni}(\mathrm{I})$ enzyme and the sulfonate group of the substrates for the forward and reverse reactions of Eq. 1. These results suggest the need to reassess how catalysis is triggered in the MCR mechanism.

\section{$\mathrm{CH}_{3}-\mathrm{SCoM}+\mathrm{HSCoB} \rightarrow \mathrm{CH}_{4}+\mathrm{CoMSSCoB} \Delta \mathrm{G}^{0}$ $\approx-30 \mathrm{~kJ} / \mathrm{mol}$ Eq. 1}

Understanding the biosynthesis of methane is important from basic energy, economic, and environmental perspectives. Methane accounts for $22 \%$ of U.S. energy consumption $(3,4)$, with half of homes using natural gas as their heating fuel. Methane is the simplest organic compound, but it has the highest energy content of any carbon-based fuel. About $90-95 \%$ of all methane on earth is produced biogenically (5). Methanogens, responsible for enzymatic synthesis of one billion tons of methane per year (6), are its major source, the balance generated by metabolism of methylmercury (7) and methylphosphonate (8). Much of the methane formed by methanogens is captured and used as an energy source by aerobic and anaerobic methanotrophic (ANME) microbes $(9,10)$. However, the increased mining of methane and industrial farming of cattle and other ruminants since the industrial revolution has created a mismatch between the sources and sinks of methane, causing its atmospheric levels to double over the past two centuries (11). This is an environmental concern related to global warming because methane is 21 times more effective at trapping heat than the other major greenhouse gas, $\mathrm{CO}_{2}$ (12).

The basic chemistry and biology of alkane activation and formation by MCR is also intriguing because of methane's strong $\mathrm{sp}^{3} \mathrm{C}-\mathrm{H}$ bonds, its low solubility in both polar and nonpolar solvents, and very high ionization energy. The selective activation and functionalization of the $\mathrm{C}-\mathrm{H}$ bond of methane was dubbed one of the holy grail reactions in chemistry (13). MCR accomplishes this reaction, as well as methane synthesis, using a reduced Ni- hydrocorphin cofactor $F_{430}$ (14-17) related to porphyrin, chlorophyll, and vitamin $\mathrm{B}_{12}$, along with second sphere amino acid residues, as catalysts. Computational (18) and experimental (19) results indicate that the methane formation and oxidation by MCR occur through a mechanism involving methyl, thiyl and disulfide anion radicals.

A variety of crystal structures of MCR in the presence (and absence) of substrates have been published (20-24). It is a multimeric enzyme composed of three subunits MCRA $(\alpha), \operatorname{MCRB}(\beta)$ and MCRG $(\gamma)$ in an $\alpha_{2} \beta_{2} \gamma_{2}$ conformation with a reduced hydrocorphin $\mathrm{Ni}$ cofactor $\mathrm{F}_{430}$. buried at the end of a $30 \AA$ long substrate channel. The $\mathrm{F}_{430}$ is anchored via a combination of electrostatic and $\mathrm{H}$ bond interactions between the carboxylate side chains and the protein backbone (Figure 1). A weak distal $\mathrm{Ni}-\mathrm{O}$ bond $\left(\mathrm{O}-\alpha^{\prime} \mathrm{Gln}\right)$ is present in all forms of the $\mathrm{Ni}$ (II) enzyme as well as the $\mathrm{Ni}(\mathrm{I})$ states, MCRred1, MCRred1-silent and MCR-Me $(20,25)$. The coordination environment of the different states of MCR are shown in Figure 2. The Gln residue moves in ( $2.1 \AA, 6$ coordinate) or away (2.3 $\AA 5$ coordinate) based on the presence or absence of a proximal axial ligand to the $\mathrm{Ni}$-center and may play a role in fine tuning the redox potential of the Ni-center and/or provide stability during catalysis (20). Two moles of $\mathrm{F}_{430}$ bind the hexameric protein at identical but distinct substrate binding sites separated by $50 \AA$. The catalytic Ni site is accessible only through this channel and only to small molecules up to a diameter of $6 \AA$ (20).

Regarding binding of CoM, the crystal structures of the Ni(II)-MCRred1-silent and MCRox1-silent states show its thiolate anchored by binding axially to the $\mathrm{Ni}(\mathrm{II})$ on one side and its negatively charged sulfonate group forming a salt bridge to the guanidinium group of Arg- $\gamma 120$ $(20,21)$ (Figure 1). XAS results similarly indicate $S$ coordination to the $\mathrm{Ni}$ in the MCRox1 and MCRox1-silent states, while the MCR-silent state (with CoMSSCoB bound) fits best with $4 \mathrm{~N}$ ligands and $2 \mathrm{~N} / \mathrm{O}$ ligands in the axial position to give a hexacoordinate Ni-center $(25,26)$ (Fig. 2). Ni K preedge and EXAFS data and time-dependent DFT (TD-DFT) calculations also reveal the axial Ni-S bond from the thiolate of CoMSH in the Ni(II) MCRred1-silent and MCRox1-silent states (27). Additionally, this Ni-thiolate appears to interact with a water molecule that bridges $\mathrm{CoMSH}$ and 
HSCoB and forms hydrogen bonds to the hydroxyl groups of Tyr- $\alpha 333$ and Tyr- $\beta 367$ (21) (Figure 1); however, Grabarse et. al speculate that due to the extremely hydrophobic nature of the pocket there cannot be a solvent molecule trapped between the CoMS-Ni(II) and HSCoB in the MCRox1-silent structure but rather a methyl radical generated during X-ray exposure of the crystal (21).

HSCoB hangs down the substrate binding channel tethered by electrostatic interactions between its negatively charged threonine phosphate moiety and five positively charged amino acids. Its heptanoyl $\left[\left(\mathrm{CH}_{2}\right)_{6}-\mathrm{CO}-\right]$ arm stretches over $16 \AA$ in Van der Waals contact with several hydrophobic residues, namely Phe- $\alpha 330$, Tyr- $\alpha 333$, Phe- $\alpha 443$, Phe- $\beta 361$, and Tyr- $\beta 367$ positioned along the substrate binding pocket (Figure 1), At its end, the $\mathrm{HSCoB}$ thiol group is $8.8 \AA$ from the $\mathrm{Ni}$-center and interacts with the side chain nitrogen of Asn- $\alpha 481$, the main chain peptide nitrogen of Val- $\alpha 482$, and a bridging water molecule. Asn- $\alpha 481$ is within hydrogen bond distance of the sulfur in the post translationally modified thioglycine (TGly)- $\alpha 445$ (20).

Crystal structures show that various $\mathrm{HSCoB}_{5-9}$ analogs are anchored at an annulus of charged residues at the top of the substrate channel and adopt similar positions as they thread into the channel toward the Ni-cofactor (24). The thiol group of the slow substrate $\mathrm{HS}-\mathrm{CoB}_{6}$ situates at the same position as that of the native substrate, i.e. 8.8 $\AA$ from the Ni, leaving a $6.4 \AA$ gap between the thiol group of HSCoB and the Ni-bound S of CoM. Since a methyl group of $\mathrm{CH}_{3}-\mathrm{SCoM}$ cannot bridge this large gap (28), a conformational change was proposed to allow $\mathrm{HSCoB}$ to penetrate deeper in the substrate channel towards the $\mathrm{Ni}$ ion. The $\mathrm{HSCoB}_{5}$ thiol group rests $9.3 \AA$ from the $\mathrm{Ni}$ as would be expected, while the $\mathrm{SH}$ of $\mathrm{CoB}_{8} \mathrm{SH} / \mathrm{CoB}_{9} \mathrm{~S}$ are located $5.9-6.2 \AA$ from the $\mathrm{Ni}$ of $\mathrm{F}_{430}$. The crystal structures of MCR with the CoBxSH analogs did not reveal any of the conformational changes proposed to occur during catalysis, suggesting a more important role for methyl-SCoM, CoMSH and the oxidation states of the $\mathrm{Ni}-\mathrm{F}_{430}$ in the catalytic cycle (24) (Figure 2). Furthermore, the structure of the MCR-CoMSSCoB (MCR-silent) reveals the $\mathrm{HSCoB}$ portion in virtually the same place as in MCRox1-silent $(29,30)$. Thus, the large distance in these structures $(24,29,30)$ between the
HSCoB hydrogen atom to be abstracted and the methyl group, which is proposed to undergo homolytic fission promoted by a Ni(I)-SCoM interaction, poses a conundrum for all published MCR catalytic mechanisms, highlighted in Figure $3 a$.

One significant issue is that all published crystal structures are of inactive $\mathrm{Ni}(\mathrm{II})$ or a methyl$\mathrm{Ni}(\mathrm{III})$ state - none are available for the active $\mathrm{Ni}(\mathrm{I})$ state. In our studies of the binding of HSCoB analogs (24), although the crystallizations were set up with the MCR solution predominantly in the $\mathrm{Ni}(\mathrm{I})$-MCRred1 state, by the time X-ray diffraction data were collected they had undergone oxidation to the Ni(II)-MCRred1-silent state, as assessed by single crystal UV-visible microspectrophotometry; furthermore, following data collection there was no evidence for photoreduction of the Ni(II) back to $\mathrm{Ni}(\mathrm{I})$ in any of the crystals. Attempts to photoreduce the crystals using different wavelengths and temperatures were also unsuccessful.

Thus, spectroscopic studies are crucial to obtaining an accurate description of the coordination chemistry of the Ni(I) state. In this respect, X-ray absorption spectroscopy (XAS) is highly significant because it provides extremely precise measurement of the $\mathrm{Ni}$ oxidation state and metal-ligand bond distances as well as discrimination between thiolate and nitrogen or oxygen ligation. Furthermore, these experiments can be carried out under strictly anaerobic conditions. Similarly, electron paramagnetic resonance (EPR)-based studies provide an independent view of the $\mathrm{d}^{9} \mathrm{Ni}(\mathrm{I})$ state. For example, on the basis of EPR, electron nuclear double resonance (ENDOR) and quantum mechanical calculations, Hinderberger et.al, proposed that the thioether-S of methyl-SCoM and one of the $-\mathrm{H}$ atoms of the methyl group are between $3.45-3.75 \AA$ and $5.35-5.65 \AA$ respectively from the Ni-center (31). This binding mode does not bring the thioether-S within bonding distance of the Ni. In this contribution, we add near infrared (NIR) spectroscopy to characterize the active $\mathrm{Ni}(\mathrm{I})$ state of MCR. The spectroscopic, kinetic, structural and computational studies described here establish that methyl-SCoM binds to the active $\mathrm{Ni}(\mathrm{I})$ state of MCR through its sulfonate, forming a hexacoordinate Ni(I) complex. This is unusualmost $\mathrm{Ni}(\mathrm{I})$ complexes are four- or five-coordinate 
(32); we are aware of only one other structurally characterized six-coordinate model $\mathrm{Ni}(\mathrm{I})$ complex (33). Here we also suggest a solution to the apparent conundrum of how the methyl radical can attack the $\mathrm{H}$ of HSCoB. As shown in Fig. 3b, we propose a revised mechanism for MCR catalysis in which methyl-SCoM binds to $\mathrm{Ni}(\mathrm{I})$ through its sulfonate group. We suggest that this is the state from which catalysis ensues.

\section{RESULTS}

Changes in near infrared bands on addition of substrates: Comparison among the various substrates. In the UV-visible region, $\mathrm{Ni}(\mathrm{I})$ has a characteristic absorbance at $385 \mathrm{~nm}$ which changes to $420 / 445$ (sh) $\mathrm{nm}$ on oxidation to $\mathrm{Ni}(\mathrm{II})$ or $\mathrm{Ni}(\mathrm{III})$. Ni(I)-MCRred1 also exhibits characteristic d-d transition in the near infrared (NIR) region of the electromagnetic spectrum that are absent in $\mathrm{Ni}$ (II) states like MCRred1-silent. Addition of substrates, CoMSSCoB and methyl-SCoM to $50 \mu \mathrm{M}$ Ni(I)MCRred1 (between 65-70 \% $\mathrm{Ni}(\mathrm{I})$ for various purifications) elicits significant changes in these NIR bands over a timeframe that the $385 \mathrm{~nm} \mathrm{UV-}$ visible band associated with $\mathrm{Ni}(\mathrm{I})$ does not change. Thus, we attribute these changes to shifts in the d-d orbitals of $\mathrm{Ni}(\mathrm{I})$ that can be monitored to elucidate the nature of substrate binding.

Addition of HSCoB alone does not elicit NIR changes. However, titration of Ni(I)-MCRred1 (50 $\mu \mathrm{M})$ with the first substrate in the reverse reaction, CoMSSCoB or $\mathrm{CoMSSCoB}_{6}(0-500 \mu \mathrm{M})$, shifts the broad $700 \mathrm{~nm}$ peak to $\sim 750 \mathrm{~nm}$ (Figure 4A). The breadth of these $d-d$ transitions makes it difficult to precisely monitor the wavelength maxima due to overlap. We employed difference spectra to more accurately quantify these changes at the exact wavelengths. Difference spectra (Figure 4B) show that the decrease in absorbance at $700 \mathrm{~nm}$ is associated with an increase at $768 \mathrm{~nm}$ and $850 \mathrm{~nm}$ for both substrates. The absorbance at $385 \mathrm{~nm}$ characteristic of $\mathrm{Ni}(\mathrm{I})$ in MCRred1 remains unchanged as the NIR spectra shift demonstrating that the decrease in absorbance at $700 \mathrm{~nm}$ is due to binding and not due to oxidation of $\mathrm{Ni}(\mathrm{I})$ (Figure 4C) associated with catalysis. Oxidation of $\mathrm{Ni}(\mathrm{I})$ to $\mathrm{Ni}(\mathrm{II})$ occurs over a longer time frame associated with decay of the NIR bands as the $385 \mathrm{~nm}$ band shifts to $420 \mathrm{~nm}$ (Figure S5) Thus, these NIR changes can confidently be assigned to $d-d$ changes associated with substrate binding alone.
Interestingly, addition of methyl-SCoM to MCRred1 gives rise to the same NIR spectral changes with the absorbance at $385 \mathrm{~nm}$ remaining unchanged. These changes in $\mathrm{d}-\mathrm{d}$ transitions suggest that $\mathrm{CoMSSCoB}_{2} \mathrm{CoMSSCoB}_{6}$, and methyl-SCoM all bind in a similar fashion within the enzyme pocket.

On the other hand, addition of CoMSH does not result in any NIR spectral shifts. Ni(I)-MCRred1 is purified in the presence of $10 \mathrm{mM}$ CoMSH to stabilize the active enzyme. These preparations result in a mixture of $\mathrm{Ni}(\mathrm{I})$ and $\mathrm{Ni}(\mathrm{II})$, which can be precisely quantified by the relative absorbances of these states. The Ni(II)-MCRred1 state contains tightly bound $\mathrm{Ni}(\mathrm{II})-\mathrm{SCoM}$ that is difficult to remove by dialysis, leading to a quantifiable proportion of the enzyme containing a Ni(II)thiolate with the sulfonate bound to Arg- $\gamma 120$ as observed in various crystal structures (described above). Previous XAS studies have shown Ni(I) in MCRred1 to be 5-coordinate in the presence of CoMSH (25). Thus, the lack of NIR changes upon addition of CoMSH results from the stability of five-coordinate $\mathrm{Ni}(\mathrm{I})$-MCRred1 or an alternate binding conformation in the substrate pocket.

Our interpretation of these substrate-induced spectral changes is that addition of $\mathrm{HSCoB}$ alone or CoMSH does not result in any change in the $\mathrm{Ni}(\mathrm{I})$ d-d bands, suggesting that these substrates do not alter the five-coordinate $\mathrm{Ni}(\mathrm{I})$ state. On the other hand, addition of methyl-SCoM or either of the heterodisulfide substrates results in formation of a similar six-coordinate $\mathrm{Ni}(\mathrm{I})$ state. These conclusions are validated by XAS and computational results, described below.

Quantum chemical truncated models (Figure 5) of the MCR active site containing $\mathrm{Ni}(\mathrm{I})$ binding either CoMSSCoB (model 1) or methyl-SCoM (the latter with or without $\mathrm{CoBSH}$, models 2 and 3, respectively) were investigated to elucidate the Nisulfonate interaction and its effect on the NIR spectra. Based on the $\mathrm{p} K_{\mathrm{a}}$ measurements reported below, the sulfonate groups of methyl-SCoM and CoMSSCoB were modeled as deprotonated. Because all models truncated the SHCoB at the second carbon, the protonation of the phosphate group does not affect these calculations. The geometries of the optimized structural models are reported in Figure 5 along with relevant geometrical parameters. Additional geometrical parameters are summarized and compared with 
those from the $1.8 \AA$ resolution crystal structure of the MCR-product complex (pdb entry: 1HBM) in Table 1.

All models show stable complexes of $\mathrm{Ni}$ with the $\mathrm{SO}_{3}{ }^{-}$group and $\mathrm{Gln} 147$ residue via oxygen, as well as the interaction of the substrate with the $\mathrm{OH}$ groups of the Tyr residues,

The spectra of the structural models (Figure 7) for $\mathrm{Ni}$ coordination with $\mathrm{SO}_{3}^{-}$of methyl-SCoM considered in the present work were simulated in a time-dependent-DFT (TDDFT) framework and compared with the spectra of previous structural models for a Ni- $\mathrm{S}_{\mathrm{m}}$ coordination (Figure 6, models A-D). Figure 6 shows that the adopted computational setup captures well the major spectral features and, importantly, qualitatively captures the shifts in the various structures. For structures $A$ and $B$, which are $\mathrm{Ni}(\mathrm{I})$, the characteristic peak is calculated to be around $\sim 340$ $\mathrm{nm}$. As the S-S bond is broken, the $\mathrm{S}_{\mathrm{m}} \mathrm{Ni}$ bond is formed (structures $\mathrm{C}$ and $\mathrm{D}$ ) and $\mathrm{Ni}$ center changes from $\mathrm{Ni}(\mathrm{I})$ to $\mathrm{Ni}$ (II) as the peak shifts towards $\sim 460$ $\mathrm{nm}$, in agreement with the experimentally observed shifts. In particular, the d-d transitions for structures $A$ and $B$ are captured at around $650 \mathrm{~nm}$ (Figure 6b). For the structures with Ni-O coordination (Figure 7 and 8), the d-d transitions in the NIR spectrum are slightly shifted to $\sim 600 \mathrm{~nm}$, with some low intensity $\mathrm{d}-\mathrm{d}$ transitions found beyond $780 \mathrm{~nm}$. These calculations suggest that the spectral features observed experimentally can be assigned to the structures exhibiting $\mathrm{Ni}-\mathrm{SO}_{3}{ }^{-}$interactions.

Binding constants for methyl-SCoM, CoMSSCoB and CoMSSCoB6. A plot of the NIR changes shows that the decrease in absorbance at $700 \mathrm{~nm}$ matches the concomitant increase at 768

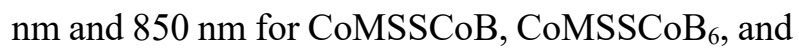
methyl-SCoM (Figure 9A) The data are fit to a one-site binding isotherm, where fraction of bound enzyme is plotted versus the concentration of substrate. For the reverse reaction substrates, the $\mathrm{K}_{\mathrm{d}}$ values are $57.4 \pm 5.4 \mu \mathrm{M}$ for CoMSSCoB and 105.3 $\pm 10.9 \mu \mathrm{M}$ for $\mathrm{CoMSSCoB}_{6}$ (Figure 9B). The $\mathrm{K}_{\mathrm{d}}$ for methyl-SCoM is $27.5 \pm 7.3 \mu \mathrm{M}$ (Figure 9C), which is similar to the value $(13 \pm 4 \mu \mathrm{M})$ obtained by fluorescence spectroscopy (34). The tighter binding for methyl-SCoM is as expected, since MCR relies on the strict binding order of substrates to initiate catalysis. The $\mathrm{K}_{\mathrm{d}}$ values for the heterodisulfide substrates are similar to that for $\mathrm{HSCoB}(90 \pm 22 \mu \mathrm{M})$ as measured by fluorimetry
(34), presumably dictated by the strong electrostatic interactions at the top of the channel between the positively charged protein residues (Figure. 1) and the carboxylate and phosphate groups of the $\mathrm{CoB}$ moiety.

The only structural feature in common among methyl-SCoM and the heterodisulfide substrates relevant to $\mathrm{Ni}$ coordination is their sulfonate group (although the sulfurs are similar - thioether and disulfide), indicating the formation of upper axial $\mathrm{Ni}-\mathrm{O}$ (sulfonate) ligand with these three substrates. Thus, we studied MCR binding to butane sulfonate, which maintains the carbon chain and the sulfonate group but lacks the $-\mathrm{S}$ atom that all canonical mechanism (as shown in Fig. 3a) postulate to bind to the $\mathrm{Ni}(\mathrm{I})$ during first step of catalysis of both forward and reverse methane synthesis reactions. Upon addition of butane sulfonate, the same NIR spectral shifts are observed as with the other substrates, but with a much higher $K_{d}$ value of 3.3 $\pm 0.6 \mathrm{mM}$ (Figure. 9D). This high value of $\mathrm{K}_{\mathrm{d}}$ can be due to the lack of the $-\mathrm{S}$ which is stabilized via hydrogen bond interactions with the Tyr-333 residue in the catalytic pocket.

Measurement of $p K_{a}$ values for the sulfonate, carboxylate, phosphate and thiol groups by acid base titrations and ${ }^{31} P$ - and ${ }^{1} H-N M R$. As a primary standard, $0.1 \mathrm{M} \mathrm{NaOH}$ was added to substrate solutions starting at $\mathrm{pH} 1$. The $\mathrm{pH}$ changes were recorded and plotted against volume of added 0.1 $\mathrm{M} \mathrm{NaOH}$ to obtain titration curves. Then, $\mathrm{pK}_{\mathrm{a}}$ values were calculated using the HendersonHasselbach equation (Eq 2) where the $\mathrm{pK}_{\mathrm{a}}$ equals the $\mathrm{pH}$ at half equivalence point.

$$
\mathrm{pH}=\mathrm{pK}_{\mathrm{a}}+\log \left(\mathrm{A}^{-} / \mathrm{HA}\right) \ldots \ldots \ldots \ldots . . \mathrm{Eq} 2
$$

The $\mathrm{pK}_{\mathrm{a}}$ of 9.4 in CoMSH is assigned to the thiol group. The sulfonate group pKa of 1.9 in $\mathrm{CoMSH}$ and 2.5 in methyl-SCoM is as expected due to the inductive effect of the methyl group (electron donating) which destabilizes the conjugate base thus increasing the $\mathrm{pK}_{\mathrm{a}}$ (Figure $\mathbf{S 1}$ ). The $\mathrm{pH}$ titration of $\mathrm{HSCoB}$ starting at $\mathrm{pH} 1.1$ yields four $\mathrm{pK}_{\mathrm{a}}$ values (Table 2A) that can be attributed to phosphate ionization-1, carboxylate, phosphate ionization-2 and the thiol group (Figure S2).

To distinguish between the carboxylate and phosphate ionization-1, ${ }^{31} \mathrm{P}-\mathrm{NMR}$ and ${ }^{1} \mathrm{H}-\mathrm{NMR}$ chemical shift changes with changes in $\mathrm{pH}$ were monitored. The pKa of 9.2 can be unambiguously ssigned to the -SH group of HSCoB (Figure S3) (Table 2B). In CoMSSCoB, the $\mathrm{pKa}$ of the 
sulfonate group could not be determined because it is presumably lower than 1 . The pKa of 1.8 in the case of the heterodisulfide is assigned to the first ionization of phosphate based on the ${ }^{31} \mathrm{P}-\mathrm{NMR}$. Figure S4

X-ray absorption studies. XAS studies, including Ni-K edge, pre-edge, and EXAFS of MCRred1 and MCRred1-silent with and without heterodisulfide substrates CoMSSCoB and $\mathrm{CoMSSCoB}_{6}$ were carried out to establish the changes in coordination around the $\mathrm{Ni}(\mathrm{I})$ in the enzyme substrate binding pocket.

MCRred1 was purified as MCRred1c (CoMSH bound) and was extensively buffer exchanged with $50 \mathrm{mM}$ Tris- $\mathrm{HCl}, \mathrm{pH} 7.6$, in an attempt to remove any bound $\mathrm{Ni}(\mathrm{I})-\mathrm{SCoM}$ and is denoted as MCRred1 in the XAS samples. The Ni(II)-MCRred1-silent sample was prepared by buffer exchange (in $50 \mathrm{mM}$ Tris-HCl, pH 7.6) of an MCRred1c sample, auto oxidized by prolonged storage in the anaerobic chamber. This MCRred1-silent is referred to as MCRred1c-silent going forward in the manuscript for clarity. Based on the UV-visible spectra, the MCred1 XAS spectra were corrected for the presence of $30 \%$ MCRred1c-silent impurity present in the sample.

Ni K-edge XAS and EXAFS of MCRred1 show that the $\mathrm{Ni}(\mathrm{I})$ is penta-coordinate with $4 \mathrm{~N}$ (ring) and 10 (axial Gln) (Figure 10 A and Table 3). On the other hand, MCRred1c-silent consists of a hexacoordinate $\mathrm{Ni}$ (II) with 4N (ring), $1 \mathrm{O}$ (axial Gln) and a $-\mathrm{S}$ ligand from covalently bound CoMSH. The covalent nature of the $\mathrm{Ni}(\mathrm{II})-\mathrm{S}$ bond prevents the loss of CoMSH during extensive buffer exchange. This is also evident in the EXAFS of MCRredlcsilent where there is a higher contribution from the $\mathrm{Ni}-\mathrm{S}$ bond and the data can be assigned to a hexacoordinated Ni(II) (Figure 10A, Table 3)

Addition of substrates, CoMSSCoB and $\mathrm{CoMSSCoB}_{6}$ to MCRred1 results in: a) decrease in the back-bonding contribution at $\sim 8334.5 \mathrm{eV}$ in the Ni-pre edge region (Figure 10 B) and a modest increase in the EXAFS and FT data. FEFF fits suggest the presence of a sixth, weaker, light atom $(\mathrm{O} / \mathrm{N})$ ligand to the $\mathrm{Ni}(\mathrm{I})$ at $\sim 2.17 \AA$ (Figure $11 \mathrm{~A}$ and $11 \mathrm{~B}$ top panel). Attempts to fit the data without the weak Ni-O component (Figure 11A and $11 \mathrm{~B}$, bottom panel) or by increasing the Ni-S coordination led to statistically poorer fits. Thus, the EXAFS data strongly indicate the formation of a hexa coordinated $\mathrm{Ni}(\mathrm{I})$ model for MCRred1 plus
CoMSSCoB or $\mathrm{CoMSSCoB}_{6}$. Both the heterodisulfide substrates are tethered to the top of the substrate binding channel via phosphate and carboxylate groups with the methylene chain of $\mathrm{CoB}$ moiety making its way into the channel, as described above and shown in Fig 1. The sulfonate group of the CoM part of the molecule is within bonding distance of the $\mathrm{Ni}(\mathrm{I})$ and is likely the sixth ligand. In contrast, addition of the heterodisulfide substrates to MCRred1c-silent shows no changes in the pre-edge or EXAFS of the enzyme (Figure 6), indicating that the heterodisulfide substrate cannot outcompete covalently bound CoMSH in the Ni(II) active site (Figure S6).

The fits for MCRred1 + CoMSSCoB and $\mathrm{CoMSSCoB}_{6}$ are significantly better and statistically relevant when a sixth lighter $\mathrm{N} / \mathrm{O}$ ligand is included. $\mathrm{A} \mathrm{Ni}(\mathrm{I})-\mathrm{OSO}_{3}$ bond is expected to result in a weak interaction, but the heterodisulfides are constrained in a fixed geometry in the substrate binding pocket with little flexibility. The sulfonate is held in position within binding distance to the $\mathrm{Ni}(\mathrm{I})$.

Absence of an increase in the Ni-S component in the FEFF fits to the EXAFS data clearly shows no additional sulfur atom ligation to $\mathrm{Ni}(\mathrm{I})$ on addition of any of the substrates. This is quite significant since all catalytic mechanisms begin with a Ni(I)-thiolate. So far, the only experimentally observed $\mathrm{Ni}(\mathrm{I})-\mathrm{S}$ interaction is with the MCRred2 form, which was generated by addition of HSCoB to MCRred1c. This interaction was previously characterized with pulse EPR and ENDOR studies (35). Similarly, our EPR spectra of the MCRred2 sample (Figure 12A, bottom spectrum) shows $40 \%$ conversion of MCRred 1 to MCRred 2 calculated from the relative intensity of the $g=2.2098$ (rhombic signal from MCRred2) and $\mathrm{g}=2.0537$ (axial signal from MCRred1) (Table 3).

EPR spectra of the split XAS samples run in parallel show sharpening of the hyperfine signals arising from the ring nitrogens on addition of CoMSSCoB, $\mathrm{CoMSSCoB}_{6}$, methyl-SCoM and But- $\mathrm{SO}_{3}$ (Figure 12 B) but not with $\mathrm{CoMSH}$ (Figure $12 \mathrm{~A}$ bottom spectrum). The $\mathrm{g}$ values (2.2201 and 2.0510) are consistent with previously published EPR data, as summarized (30). As shown earlier (36), methyl-SCoM binding results in sharpening of the superhyperfine features. This sharpening is also observed with addition of $\mathrm{CoMSSCoB}, \mathrm{CoMSSC}_{6} \mathrm{~B}_{6}$ and $\mathrm{But}_{-} \mathrm{SO}_{3}$ suggesting 
that they bind similarly to MCR. To explain this sharpening of the superhyperfine lines, one option is that it results from movement of the $\mathrm{Ni}(\mathrm{I})$ into the plane of the $\mathrm{F}_{430}$ corphinoid ring due to the conversion of a penta to a hexacoordinate $\mathrm{Ni}(\mathrm{I})$ complex. However, the hyperfine splitting values $\left(A_{N}\right.$ and $\left.A_{N i}\right)$ of MCRred1 and the methyl-SCoM bound MCRred1m are comparable (37). Perhaps sharpening of the superhyperfine lines results from a $\mathrm{Ni}(\mathrm{I})$-substrate interaction that reduces the micro heterogeneity around the $\mathrm{Ni}(\mathrm{I})$ by restricting it to a fixed conformation as the pentacoordinated $\mathrm{Ni}(\mathrm{I})$ converts to a hexacoordinated $\mathrm{Ni}(\mathrm{I})$ complex with a weak Ni(I)-O-sulfonate interaction. Binding of CoMSH ( Figure $12 \mathrm{~A}$, middle spectrum) does not exhibit line sharpening observed with the other substrates, consistent with it not forming an axial $\mathrm{Ni}(\mathrm{I})-\mathrm{O}$ sulfonate complex.

The structural assignments are also consistent with the geometries determined by quantum mechanical calculations of the model systems. The summary of the relevant geometric distances for the three models and the crystal structure 1HBM are summarized in Table 1.

As shown in Fig. 5 and Table 1, the Ni-O distance, between $\mathrm{F}_{430}$ and $\mathrm{O}-\mathrm{G} \ln 147$ is similar in the 3 calculated structures at about $2 \AA$, whereas the $\mathrm{Ni}-\mathrm{O}$ between $\mathrm{F}_{430}$ and the $\mathrm{SO}_{3}{ }^{-}$group varies, with distance of $\sim 2.4$ for the models 1 and 2 , and is elongated to $2.7 \AA$ in model 3 . Similarly, the distances from the $\mathrm{Ni}$ to the $\mathrm{S}$ atom in the $\mathrm{SO}_{3}{ }^{-}$ group is $\sim 0.3 \AA$ longer in model 3 , compared to models 1 and 2 . In comparison, the crystal structure shows a longer bond between $\mathrm{Ni}$ and $\mathrm{G} \ln 147$ (2.35 $\AA$ ), but a slightly shorter distance to the nearest oxygen of the $\mathrm{SO}_{3}^{-}$group $(2.29 \AA)$. The distances between the Ni center and the $\mathrm{S}_{\mathrm{b}}$ of HSCoB remains largely unchanged in the three models in Fig. 5 and very similar to the crystal structure; however, the $\mathrm{Ni}-\mathrm{S}_{\mathrm{m}}$ distance varies from $\sim 6.1 \AA$ in $\mathrm{CoBSH}-$ methyl-SCoM to $\sim 7 \AA$ in $\mathrm{CoBSSCoM}+\mathrm{CH}_{4}$.

Because no crystal structure is available for methyl-SCoM-bound MCRred1, the position of the $\mathrm{CH}_{3}$ group in methyl-SCoM cannot be verified. However, overlap of the calculated structures of CoBSH-methyl-SCoM (Figure 5B) show that even in a state where methyl-SCoM would bind to $\mathrm{Ni}$ via the $\mathrm{SO}_{3}^{-}$group, the $\mathrm{CH}_{3}$ group can fit in a cavity between the Tyr333, Phe330 and HSCoB, nestled near the thiol group of $\mathrm{HSCoB}$ (Fig. 5C).
Previous theoretical models that employed a truncated methyl disulfide representation of methyl-SCoM (Fig. 6) where the interaction with $\mathrm{Ni}$ is considered via the $\mathrm{S}_{\mathrm{m}}$ atom, show a Ni-S distance of $\sim 3.7 \AA$, and a much longer $\mathrm{Ni}$ $\mathrm{O}(\mathrm{G} \ln 147)$ distance of $\sim 3.8 \AA$ (38). Instead, CoMSSCoB (modeled as ethylS-Smethyl) exhibits a Ni-Sm distance of $\sim 4 \AA$.

Interestingly, the electronic structure of the $\mathrm{Ni}$ center in the present calculations differs from the previous models $(19,39)$. In these prior models, a single unpaired electron is localized on the $\mathrm{Ni}$ center, as characterized by Mulliken spin analysis resulting in spin $\sim 0.9$. The lowest electronic state for the present calculations shows that the overall spin on the Ni center is persistently $\sim 1.6$, with an antiferromagnetically coupled electron delocalized on the carbon atoms in the $\mathrm{F}_{430}$ ring, giving an overall state $\mathrm{Ni}(\mathrm{I})$, even though the metal center itself exhibits $\mathrm{Ni}$ (II) like character. The spin assignments for the new structures are reported in Table 4. This unusual electronic state of the Ni may explain the uncommon hexa-coordination in the $\mathrm{Ni}(\mathrm{I})$.

\section{DISCUSSION}

The position of CoBSH in previous crystal structures $(29,30)$ poses a conundrum for all published MCR catalytic mechanisms. Basically, the question is: how can a methyl radical generated from a Ni-thioether interaction with methyl-SCoM at the nickel abstract the $\mathrm{H}$ of HSCoB when the reactive sulfurs of the two substrates are $6.4 \AA$ apart? The results described here suggest a solution-methyl-SCoM, the first substrate in the forward reaction, forms a six-coordinate $\mathrm{Ni}(\mathrm{I})-\mathrm{O}$ complex between a sulfonate oxygen group and the $\mathrm{Ni}(\mathrm{I})$ center of $\mathrm{F}_{430}$. Similarly, our work suggests that the first substrate in the reverse reaction, CoMSSCoB, forms a Ni(I)-sulfonate interaction.

While the thiolate of $\mathrm{CoMS}^{-}$appears to bind tightly to the $\mathrm{Ni}$ (II) states of MCR, in the absence of co-substrate (HSCoB) (Figure 1A), it does not appear to bind to the $\mathrm{Ni}(\mathrm{I})$-state. Furthermore, addition of CoMSH to MCRred1 does not alter its $\mathrm{Ni}(\mathrm{I})$ NIR or XAS spectra, indicating that MCRred1 is five-coordinate, with $4 \mathrm{~N}$ from the hydrocorphin ring and an $\mathrm{O}$ from Gln- $\alpha$ ' 147 . This assignment is supported by EXAFS data of the Ni(I)-MCRred $1 \mathrm{~m}$ and MCRred1c states (21). Ni K pre-edge and EXAFS data presented here in addition to time 
dependent DFT (TD-DFT) calculations also reinforce the five-coordinate nature of the $\mathrm{Ni}(\mathrm{I})$ center when MCRred1 reacts with CoMSH (27). Furthermore, when MCRred1 is reacted with ${ }^{33} \mathrm{~S}$ substituted $\mathrm{CoM}^{33} \mathrm{SH}$, no line broadening in the $\mathrm{X}$ band EPR spectrum is observed (28).

Unlike the neutral effect in the NIR spectra of adding CoMSH to Ni(I)-MCR, addition of methylSCoM, butylsulfonate, and the heterodisulfides CoMSSCoB and $\mathrm{CoMSSCoB}_{6}$ to MCRred1 elicits changes marked in the $\mathrm{d}-\mathrm{d}$ transitions of the $\mathrm{Ni}(\mathrm{I})$ center that reveal the $K_{d}$ values for each of the substrates. Our NIR studies are complemented by XAS, quantum mechanical calculations and TDDFT studies to characterize the $\mathrm{Ni}(\mathrm{I})$ ligand interaction that arises on binding. Furthermore, unlike computational models described so far, which omitted the sulfonate group of methylSCoM using methane thiol as the substrate (38), we included this in our computations.

Based on these studies, we propose an alternate model for methyl-SCoM binding to MCRred1 for the forward reaction (Figure 13) and a new mechanism (Fig. 3B) for the catalysis of MCR in the forward and reverse reactions. These suggestions depart from canonical mechanisms, e.g. Fig. 3A, which propose a Ni-S (thioether) interaction with methyl-SCoM and a Ni-S (disulfide) interaction with CoMSSCoB. Our alternative model mimics the structure of the CoMSSCoB-product complex with $\mathrm{Ni}(\mathrm{II})-\mathrm{MCR}$ and positions the methyl thioether group adjacent to the hydrogen atom of $\mathrm{HSCoB}$, as shown in Figure 5.

Thus, as shown in Figure 5, we propose that the structures of the Ni(I)-methyl-SCoM/HSCoB and the CoMSSCoB complexes mimic that of the X-ray crystal structure of the MCR-silent state, in which the heterodisulfide binds with one $-\mathrm{O}$ of the sulfonate axially coordinated to the $\mathrm{Ni}(\mathrm{II})$ center and makes H-bond contacts with Tyr- $\alpha 333$. The second $-\mathrm{O}$ is hydrogen bonded to the lactam ring of the cofactor $\mathrm{F}_{430}$ and to the hydroxyl group of Tyr$\beta 367$ and the third $-\mathrm{O}$ interacts with a water molecule. Similarly, we propose that the CoBSpart of the heterodisulfide substrate makes the same electrostatic and Van der Waals contacts as the $\mathrm{HSCoB}$ at the top of the channel and along the annular arrangement of the hydrophobic residues along the substrate channel. The $-\mathrm{S}$ of the CoBmoiety of the heterodisulfide is then placed in the same position as that of $\mathrm{HSCOB}$ in the crystal structure. (20)

Thus, in Step 1 of both the canonical (Fig. 3A) and our proposed (Fig. 3B) mechanisms, Ni(I)MCRred1 (A) first binds methyl-CoM and then $\mathrm{CoBSH}$ to form the productive ternary complex (B) (34). The shaded box(es) in 3A will be addressed below.

In Step 2, Ni(I) transfers an electron to methylSCoM to promote homolytic cleavage of the C-S bond of methyl-SCoM forming intermediate (C) with the $\mathrm{H}$ atom of $\mathrm{HSCoB}$ positioned near the $\mathrm{CH}_{3}$ group of methyl-SCoM. In Fig. 3A, the proposed transition state (TS1) for this reaction (38) features a Ni-S (thioether) interaction; however, as described above, prior computational models omitted the sulfonate group of methyl-SCoM, thus, its involvement in the MCR mechanism obviously could not be addressed. In Fig. 3B, the methylSCoM is flipped 90 degrees with $\mathrm{Ni}(\mathrm{I})-\mathrm{O}$ (sulfonate) coordination. In both cases, a methyl radical is positioned between the thiolate sulfurs of CoMS- and the $\mathrm{H}$ of HSCoB. The mechanistic implication is in the mode of ET-direct $\mathrm{Ni} \rightarrow$ thiolate in $3 \mathrm{~A}$ and long distance from the sulfonate to the thioether in $3 \mathrm{~B}$.

While there has been active discussion in the biology, chemistry and physics communities about how it occurs, long-range ET (aka electron tunneling) of $20 \AA$ has been demonstrated in many proteins (40), such as ribonucleotide reductase $(41,42)$. Redox equivalents can be transferred even longer distances by multistep tunneling, often called hopping, through intervening amino acid side chains. The well-studied mechanism of proton coupled ET (called long-range radical transfer) in ribonucleotide reductase (42) is also instructive.

In Step 3 of methane synthesis, the methyl group abstracts a hydrogen atom from $\mathrm{HSCoB}$ to generate methane and a CoBS• radical (Species D). So far we have observed only small amounts $(\sim 6 \%)$ of a radical that we have assigned to CoBS $\bullet$ (43) presumably because unstabilized thiyl radicals are difficult to observe due to their short lifetimes and large spin-orbit coupling with the sulfur atom (44). Frey and others have used radical clocks and substrate analogs that form stabilized radicals to investigate elusive substrate radicals (45). The proposed methyl radical, which will likely be even more challenging to visualize, also has not yet been spectroscopically observed. 
In Step 4 of methane synthesis, the CoBS• radical reacts with bound $\mathrm{CoM}$ (through the thiolate, 3A, or sulfonate, 3B) to generate a disulfide anion radical (Species E), which transfers an electron back to $\mathrm{Ni}(\mathrm{II})$ to generate the $\mathrm{Ni}(\mathrm{I})$ CoMSSCoB product $(\mathbf{F})$, which we have observed by NIR and XAS spectroscopies. Dissociation of the heterodisulfide in step 5 regenerates the $\mathrm{Ni}(\mathrm{I})$ starting state (A) for the next round of catalysis.

To address the shaded portion of Fig. 3A, while Fig. 3B invokes the Ni-sulfonate as the productive complex, an alternative is that the $\mathrm{Ni}(\mathrm{I})$ sulfonate complex undergoes rearrangement to a productive Ni-S(thioether) coordination, as proposed in the canonical mechanism. We feel this rearrangement is unlikely because conversion from Species $\mathbf{A}$ to $\mathbf{B}$ is quantitative and because our results (described above) indicate that Species B (Fig. 3B) is catalytically competent.

\section{METHODS}

Organism

and materials. Methanothermobacter marburgensis was obtained from the Oregon Collection of Methanogens (Portland, OR) catalog as OCM82.

All buffers, media ingredients, and other reagents were acquired from Sigma. The $\mathrm{N}_{2}$ (99.98\%), $\mathrm{CO}$ (99.99\%), $\mathrm{H}_{2} / \mathrm{CO}_{2}(80 \% / 20 \%)$, and Ultra High Purity (UHP) $\mathrm{H}_{2}(99.999 \%)$ gases were obtained from Cryogenic Gases (Grand Rapids, MI).

A stock solution of $83 \mathrm{mM}$ Ti(III) citrate was prepared by adding $0.5 \mathrm{M}$ sodium citrate to Ti(III) trichloride $(15 \% \mathrm{w} / \mathrm{v}$ in $2 \mathrm{~N}$ hydrochloric acid) under anaerobic conditions and adjusting the $\mathrm{pH}$ to 7.0 with $1 \mathrm{M}$ Tris $\mathrm{pH} 8.0$ (46). The concentration of $\mathrm{Ti}(\mathrm{III})$ citrate was determined from its UV-visible absorbance at $340 \mathrm{~nm}\left(\varepsilon=730 \mathrm{M}^{-1} \mathrm{~cm}^{-1}\right)$.

Methyl-SCoM was prepared from HSCoM and methyl iodide (47). The homodisulfides CoBS$\mathrm{SCoB}$ and $\mathrm{CoB}_{6} \mathrm{SSCoB}_{6}$ were synthesized from their respective 7-bromoheptanoic acid and 6bromohexanoic acid $(48,49)$ with a change in the final purification step. RP-PoraPak column was used with an AKTA PURE FPLC system to purify the final homodisulfide with a water/methanol gradient. The heterodisulfide $\mathrm{CoMSSCoB} 7 / 6$ was synthesized via disulfide exchange between HSCoM and $\mathrm{CoBSSCoB}$ or $\mathrm{CoB}_{6} \mathrm{SSCoB}_{6}$ in anaerobic $400 \mathrm{mM}$ potassium phosphate buffer for $2 \mathrm{~h}$ at $45^{\circ} \mathrm{C}$. The reaction was stopped by exposure to oxygen followed by purification on a RPPoraPak column connected to an AKTA PURE FPLC system. The free thiol form of $\mathrm{HSCoB}$ and $\mathrm{HSCoB}_{6}$ was generated by the reduction of the homodisulfide with tris(2-carboxyethyl) phosphine TCEP in an anaerobic chamber, purified using a RP-PoraPak column and confirmed by HPLC (Phenomenex RP-Fusion C18 column) with a $10 \mathrm{mM}$ potassium phosphate (Buffer A) and Acetonitrile (Buffer B) gradient and Mass Spectrometry

Cell growth and purification. Solutions were prepared and all steps of purification were performed under anaerobic conditions in a Vacuum Atmospheres (Hawthorne, CA) anaerobic chamber maintained under nitrogen gas at an oxygen level below $1 \mathrm{ppm}$. M. marburgensis was cultured on $\mathrm{H}_{2} / \mathrm{CO}_{2}(80 / 20 \%)$ at $65{ }^{\circ} \mathrm{C}$ in a 14 -liter fermenter (New Brunswick Scientific Co., Inc., New Brunswick, NJ) to an optical density of 7-8 at 600 $\mathrm{nm}$ in order to increase the yield of MCRisoenzyme I vs MCR- isoenzyme II. Culture media were prepared as previously described (50) with a slight modification of the sulfur and reducing source, by adding $50 \mathrm{mM}$ sodium sulfide (instead of $\mathrm{H}_{2} \mathrm{~S}$ gas) at a flow rate of $1 \mathrm{ml} / \mathrm{min}$ during the entire growth period. The cells were anaerobically harvested, resuspended in $50 \mathrm{mM}$ Tris- $\mathrm{HCl}, \mathrm{pH} 7.6$, containing $10 \mathrm{mM}$ HSCoM and $0.1 \mathrm{mM}$ Ti(III) citrate, and transferred into a 1-liter serum-stopped anaerobic high-pressure bottle. The headspace of the bottle containing the resuspended cells was purged with $\mathrm{CO}$ for 4 hours at $30^{\circ} \mathrm{C}$ to generate the active MCRred1state as previously described (51). MCR-I was purified from MCR-II using QSepharose Fast Flow resin packed in a XK 16/20 column compatible with AKTA PURE FPLC system. The buffer used was $50 \mathrm{mM}$ Tris- $\mathrm{HCl}, 10$ $\mathrm{mM}$ HSCoM pH 7.6 (Buffer A) and $50 \mathrm{mM}$ Tris$\mathrm{HCl}, 10 \mathrm{mM}$ HSCoM, $1 \mathrm{M} \mathrm{NaCl}$ pH 7.6 (Buffer B). Pure MCRred1 was collected in fractions at a gradient centered around 55\% Buffer $\mathrm{B}$. The concentration of MCRred1 was determined by UVvisible spectroscopy using extinction coefficients of 27.0 and $9.15 \mathrm{mM}^{-1} \mathrm{~cm}^{-1}$ at 385 and $420 \mathrm{~nm}$, respectively, using a multiple wavelength calculation as previously described. (50) The concentration of MCRred1-silent, which contains the inactive $\mathrm{Ni}$ (II) form of $\mathrm{F}_{430}$, was calculated using extinction coefficients of 22.0 and $12.7 \mathrm{mM}^{-}$ ${ }^{1} \mathrm{~cm}^{-1}$ at 420 and $385 \mathrm{~nm}$, respectively (50). This 
purification method yields between $65-75 \%$ MCRred1 in the active Ni(I) form and is used as is in all experiments unless otherwise stated.

UV-visible, NIR and EPR studies. Absorbance spectra were recorded in the anaerobic chamber using a diode array spectrophotometer HP-8453 instrument. EPR spectra were recorded on a Bruker EMX spectrometer (Bruker Biospin Corp., Billerica, MA), equipped with an Oxford ITC4 temperature controller, a Hewlett-Packard model 5340 automatic frequency counter, and Bruker gauss meter. The EPR spectroscopic parameters included the following: temperature, $100 \mathrm{~K}$; microwave power, 10 milliwatt; microwave frequency, 9.43GHz; receiver gain, 2104; modulation amplitude, $10.0 \mathrm{G}$; modulation frequency, $100 \mathrm{kHz}$. Spin concentration was determined by double integration of the sample spectrum obtained under non saturating conditions and comparison to that of $1 \mathrm{mM}$ copper perchlorate standard. All samples for EPR spectroscopy were prepared in $50 \mathrm{mM}$ Tris- $\mathrm{HCl}, \mathrm{pH}$ 7.6, in a Vacuum Atmospheres anaerobic chamber.

Determination of dissociation constants. The interaction of substrates with MCR was determined by monitoring changes in the Near-IR spectrum of active $\mathrm{Ni}(\mathrm{I})$ in MCR red1. The enzyme used was prepared by removing $\mathrm{HSCoM}$ and $\mathrm{Ti}$ (III) citrate from MCR by buffer exchange with $50 \mathrm{mM}$ Tris$\mathrm{HCl}, \mathrm{pH} 7.6$, using Amicon Ultra 15 centrifuge filter units with a $30-\mathrm{kDa}$ cut-off (Millipore).

$\mathrm{CoMSSCoB} \mathrm{CoMSSCoB}_{6}$, or methyl-SCoM $(0-500 \mu \mathrm{M})$ was added in small increments to 50 $\mu \mathrm{M} \mathrm{MCR}_{\text {red1 }}$ and the changes in the NIR spectra were measured. $(0-10 \mathrm{mM})$ But- $\mathrm{SO}_{3}$ or $\mathrm{HSCoM}$ was added to $50 \mu \mathrm{M}$ MCRred1-Ni(I) in order to monitor the changes induced due to substrate binding. The changes in absorbance $(700 \mathrm{~nm}, 768$ $\mathrm{nm}$ and $850 \mathrm{~nm}$ ) were plotted against substrate concentration and fit to a one site binding isotherm to obtain the dissociation constants for the various substrates. Instantaneous changes in absorbance were recorded in order to study binding and the titration data was collected over 5 min wherein no redox change with $\mathrm{Ni}(\mathrm{I})$ was observed.

$\boldsymbol{X} \boldsymbol{A S}$. The Ni K-edge XAS studies on MCR were measured at the Stanford Synchrotron Radiation Lightsource (SSRL) on the unfocused 20-pole $2 \mathrm{~T}$ wiggler sidestation beamline 7-3 under nonstandard ring conditions of $3 \mathrm{GeV}$ and $\sim 500 \mathrm{~mA}$ (low-alpha operations mode at SSRL). A Si(220) double crystal monochromator was used for energy selection. The no-M0 mirror configuration was used and components of higher harmonics were rejected by detuning the monochromator by $\sim 30 \%$. All samples were measured as solutions, which were transferred to $1 \mathrm{~mm}$ Delrin XAS cells with 1 mil Kapton tape windows under anaerobic conditions and were immediately frozen after preparation and stored under liquid $\mathrm{N}_{2}$. During data collection, samples were maintained at a constant temperature of $\sim 10 \mathrm{~K}$ using a closed-cycle CryoIndustries liquid Helium cryocooler. Data were measured to $\mathrm{k}=13 \AA^{-1}$ (fluorescence mode) using a Canberra Ge 30-element array detector. Internal energy calibration was accomplished by simultaneous measurement of the absorption of a $\mathrm{Ni}$ foil placed between two ionization chambers situated after the sample. The first inflection point of the foil spectrum was fixed at $8331.6 \mathrm{eV}$. The samples were monitored for photoreduction and a fresh spot was chosen for data collection after every three scans. However, no visual change in the rising edge energy position or the pre-edge features (associated with the $\mathrm{Ni}(\mathrm{I})$ and $\mathrm{Ni}(\mathrm{II})$ forms) were observed over successive scans, indicating that all the samples were resistant to photoreduction under the reduced current experimental conditions. Data presented here have been averaged over 12-scans or more, depending on the species. Data were processed by fitting a second order polynomial to the pre-edge region and subtracting this from the entire spectrum as background. A four-region spline of orders 2, 3, 3 and 3 was used to model the smoothly decaying post-edge region. The data were normalized by subtracting the cubic spline and assigning the edge jump to 1.0 at $8335 \mathrm{eV}$ using the Pyspline (52) program. Data were then renormalized in Kaleidagraph for comparison and quantification purposes.

Theoretical EXAFS signals $\chi(\mathrm{k})$ were calculated by using FEFF (Macintosh version 8.4) (53-55). Initial structural model for MCR was obtained from the crystal structure, and modified in Avogadro to consider O- and S- axial ligands (56). The input structure was improved based on preliminary EXAFS fit parameters to generate more accurate theoretical EXAFS signals. Data fitting was performed in EXAFSPAK (57). The structural parameters varied during the fitting process were the bond distance (R) and the bond variance $\sigma^{2}$, which is related to the Debye-Waller factor 
resulting from thermal motion, and static disorder of the absorbing and scattering atoms. The nonstructural parameter $\Delta \mathrm{E}_{0}\left(\mathrm{E}_{0}\right.$ is the energy at which $\mathrm{k}=0$ ) was also allowed to vary but was restricted to a common value for every component in a given fit. Coordination numbers were systematically varied in the course of the fit but were fixed within a given fit. The fits to the MCRred1-silent yielded metrical parameters nearly identical to those reported earlier. The presence of a MCRred1-silent in the reduced MCRred1 was accounted for by including a fixed 0.4 coordination number Ni-S path fixed at the distance obtained from the MCRred1-silent fit.

$140 \mu \mathrm{L}$ samples of MCR red1 [70\% Ni(I)] 600 $\mu \mathrm{M}$ incubated with various substrates CoMSSCoB (20 mM), CoMSSCoB6 (30 mM), methyl-SCoM $(10 \mathrm{mM}), \mathrm{But}_{-} \mathrm{SO}_{3}(40 \mathrm{mM})$ or HSCoM $(40 \mathrm{mM})$ and MCR red $170 \% \mathrm{Ni}(\mathrm{I})](600 \mu \mathrm{M})+\mathrm{HSCoM}$ $(10 \mathrm{mM})+\mathrm{CoB} 7 \mathrm{SH} / \mathrm{CoB} 6 \mathrm{SH}(20 \mathrm{mM})$ were prepared in $50 \mathrm{mM}$ Tris- $\mathrm{HCl} \mathrm{pH} 7.6$ in $40 \%$ Glycerol anaerobically. $90 \mathrm{uL}$ of each sample was frozen in a XAS cell and $50 \mathrm{uL}$ of the same sample added to $100 \mu \mathrm{L}$ of $50 \mathrm{mM}$ Tris- $\mathrm{HCl} \mathrm{pH} 7.6$ was frozen in EPR tubes for measurement.

pKa measurements. pKa measurements of the various substrates was carried out using acid base titrations with $0.1 \mathrm{M}$ standard sodium hydroxide solution (Sigma) to obtain titration curves. ${ }^{31} \mathrm{P}$ NMR and ${ }^{1} \mathrm{H}-\mathrm{NMR}$ were measured at various $\mathrm{pH}$ values for all the substrates and the changes in chemical shifts with $\mathrm{pH}$ were recorded. $\mathrm{pKa}$ values for the various functional groups (carboxylate, phosphate and thiol) were obtained by plotting chemical shifts as a function of $\mathrm{pH}$.

Computational studies. Quantum mechanical calculations were done using the NWChem program (58), employing DFT methodology. All structures were optimized using the $\operatorname{B} 3 \operatorname{LYP}(59,60)$ functional and the dispersion correction was added using Grimme's D3 correction (61). All non-metal atoms were represented with the 6-31G* Gaussian basis set (62), and for the Ni center we used lanl2dz ECP basis set (63). The structures were extracted from the crystal structure deposited in the PDB bank under code 1HBM. Points of truncation from the full structure are marked with an asterisks in Figures 5 and 6 where the model is shown. The truncated bonds were terminated with hydrogens. In the geometry optimization procedure, the heavy atoms at the truncated points were fixed in space. The structures were optimized in gas phase.

The UV vis spectra were calculated using TDDFT (64-66) approach in NWChem, using the RPA approximation. The wave functions were optimized at the same level of theory used in the geometry optimization, and a total of 50 excited states were calculated and used in the reconstruction of the spectra, using Gaussian broadening functions.

\author{
ABBREVIATIONS \\ The abbreviations used are: AOM, anaerobic oxidation of methane; HSCoB, Coenzyme B, N-7- \\ mercaptoheptanoylthreonine phosphate; $\mathrm{HSCoB}_{6} ; \mathrm{N}-6$-mercaptohexanoylthreonine phosphate; EPR, \\ electron paramagnetic resonance; ENDOR, electron nuclear double resonance; ET, electron transfer; \\ MCD, magnetic circular dichroism; MCR, methyl-CoM Reductase; methyl-SCoM, S-methyl-2- \\ mercaptoethane sulfonate; $\mathrm{But}_{-} \mathrm{SO}_{3}$, butane sulfonate; $\mathrm{CoMSH}$, 2-mercaptoethane sulfonate; CoMSSCoB, \\ heterodisulfide of coenzyme M and coenzyme B, NIR, near infrared; RR, Resonance Raman \\ spectroscopy; TS, transition state; XAS, X-ray absorption spectroscopy EXAFS, Extended X-ray \\ Absorption Fourier Transform Spectroscopy; NMR, Nuclear Magnetic Resonance Spectroscopy
}

\title{
ACKNOWLEDGMENTS
}

The content is solely the responsibility of the authors and does not necessarily represent the official views of the Department of Energy.

\section{DATA AVAILABILITY}

The data are all contained in this manuscript.

\section{CONFLICT OF INTEREST}

The authors declare that they have no conflicts of interest with the contents of this article. 
bioRxiv preprint doi: https://doi.org/10.1101/2021.01.25.428124; this version posted January 26, 2021. The copyright holder for this preprint

(which was not certified by peer review) is the author/funder, who has granted bioRxiv a license to display the preprint in perpetuity. It is made available under aCC-BY-NC-ND 4.0 International license.

Substrate binding via nickel-sulfonate to methyl-SCoM reductase

\section{REFERENCES}

1. Ankel-Fuchs, D., and Thauer, R. K. (1986) Methane formation from methyl-coenzyme M in a system containing methyl-coenzyme $\mathrm{M}$ reductase, component $\mathrm{B}$ and reduced cobalamin. Eur J Biochem 156, 171-177

2. Shima, S., and Thauer, R. K. (2005) Methyl-coenzyme M reductase and the anaerobic oxidation of methane in methanotrophic Archaea. Curr Opin Microbiol 8, 643-648

3. DeLong, E. F. (2000). Nature 407, 577-579

4. $\quad$ Blake, D. R., and Sherwood Rowland, F. (1988). Science 239, 1129-1131

5. Atreya, S. K., Mahaffy, P. R., and Wong, A. (2007) Methane and related trace species on Mars: Origin, loss, implications for life, and habitability. Planetary and Space Science 55, 358-369

6. Thauer, R. K. (1998) Biochemistry of methanogenesis: a tribute to Marjory Stephenson. Microbiology 144, 2377-2406

7. Hintelmann, H. (2010) Organomercurials. Their formation and pathways in the environment. Met Ions Life Sci 7, 365-401

8. Metcalf, W. W., Griffin, B. M., Cicchillo, R. M., Gao, J., Janga, S. C., Cooke, H. A., Circello, B. T., Evans, B. S., Martens-Habbena, W., Stahl, D. A., and van der Donk, W. A. (2012) Synthesis of methylphosphonic acid by marine microbes: a source for methane in the aerobic ocean. Science 337, 1104-1107

9. (2011) Methods in Methane Metabolism, Part A . Methanogenesis, FIrst ed., Elsevier

10. (2011) Methods in Methane Metabolism, Part B. Methanotrophy, 2011/03/16 ed., Elsevier

11. Lashoff, D. A., and Ahuja, D. (1990) Relative contributions of greenhouse gas emissions to global warming. Nature 344, 213-242

12. Schimel, J. (2000) Global change - Rice, microbes and methane. Nature 403, 375, 377

13. Arndtsen, B. A., Bergman, R. G., Mobley, T. A., and Peterson, T. H. (1995) Selective intermolecular carbon-hydrogen bond activation by synthetic metal complexes in homogeneous solution. Accounts of chemical research 28, 154-162

14. Friedmann, H. C., Klein, A., and Thauer, R. K. (1991) Biochemistry of coenzyme F430, a nickel porphinoid involved in methanogensis. in Biosynthesis of Tetrapyrroles (Jordan, P. M. ed.), Elsevier Science Publishers, Amsterdam. pp 139-154

15. Diekert, G., Klee, B., and Thauer, R. K. (1980) Nickel, a component of factor $\mathrm{F}_{430}$ from Methanobacterium thermoautotrophicum. Arch. Microbiol. 124, 103-106

16. Diekert, G., Jaenchen, R., and Thauer, R. K. (1980) Biosynthetic evidence for a nickel tetrapyrrole structure of factor $\mathrm{F}_{430}$ from Methanobacterium thermoautotrophicum. FEBS Letters 119, 118-120

17. Whitman, W. B., and Wolfe, R. S. (1980) Presence of nickel in Factor F430 from Methanobacterium bryantii. Biochemical and Biophysical Research Communications 92 , 1196-1201

18. Chen, S.-L., Pelmenschikov, V., Blomberg, M. R. A., and Siegbahn, P. E. M. (2009) Is there a Ni-methyl intermediate in the mechanism of methyl-coenzyme M reductase? $J \mathrm{Am}$ Chem Soc 131, 9912-9913

19. Wongnate, T., Sliwa, D., Ginovska, B., Smith, D., Wolf, M. W., Lehnert, N., Raugei, S., and Ragsdale, S. W. (2016) The radical mechanism of biological methane synthesis by methyl-coenzyme M reductase. Science 352, 953-958 
20. Ermler, U., Grabarse, W., Shima, S., Goubeaud, M., and Thauer, R. K. (1997) Crystal structure of methyl-coenzyme M reductase: the key enzyme of biological methane formation. Science 278, 1457-1462

21. Grabarse, W., Mahlert, F., Duin, E. C., Goubeaud, M., Shima, S., Thauer, R. K., Lamzin, V., and Ermler, U. (2001) On the mechanism of biological methane formation: structural evidence for conformational changes in methyl-coenzyme $\mathrm{M}$ reductase upon substrate binding. J Mol Biol 309, 315-330

22. Grabarse, W. G., Mahlert, F., Shima, S., Thauer, R. K., and Ermler, U. (2000) Comparison of three methyl-coenzyme $\mathrm{M}$ reductases from phylogenetically distant organisms: Unusual amino acid modification, conservation and adaptation. J Mol Biol 303, 329-344

23. Cedervall, P. E., Dey, M., Li, X., Sarangi, R., Hedman, B., Ragsdale, S. W., and Wilmot, C. M. (2011) Structural analysis of a Ni-methyl species in methyl-coenzyme M reductase from Methanothermobacter marburgensis. J Am Chem Soc 133, 5626-5628

24. Cedervall, P. E., Dey, M., Pearson, A. R., Ragsdale, S. W., and Wilmot, C. M. (2010) Structural insight into methyl-coenzyme M reductase chemistry using coenzyme B analogues. Biochemistry 49, 7683-7693

25. Duin, E. C., Cosper, N. J., Mahlert, F., Thauer, R. K., and Scott, R. A. (2003) Coordination and geometry of the nickel atom in active methyl-coenzyme $M$ reductase from Methanothermobacter marburgensis as detected by X-ray absorption spectroscopy. J Biol Inorg Chem 8, 141-148

26. Tang, Q., Carrington, P. E., Horng, Y. C., Maroney, M. J., Ragsdale, S. W., and Bocian, D. F. (2002) X-ray absorption and resonance Raman studies of methyl-coenzyme M reductase indicating that ligand exchange and macrocycle reduction accompany reductive activation. J Am Chem Soc 124, 13242-13256

27. Sarangi, R., Dey, M., and Ragsdale, S. W. (2009) Geometric and electronic structures of the $\mathrm{Ni}(\mathrm{I})$ and methyl-Ni(III) intermediates of methyl-coenzyme M reductase. Biochemistry 48, 3146-3156

28. Ebner, S., Jaun, B., Goenrich, M., Thauer, R. K., and Harmer, J. (2010) Binding of coenzyme $\mathrm{B}$ induces a major conformational change in the active site of methylcoenzyme M reductase. J Am Chem Soc 132, 567-575

29. Ermler, U., Grabarse, W., Shima, S., Goubeaud, M., and Thauer, R. K. (1997) Crystal structure of methyl-Coenzyme M reductase: the key enzyme of biological methane formation. Science 278, 1457-1462

30. Grabarse, W. G., Mahlert, F., Duin, E. C., Goubeaud, M., Shima, S., Thauer, R. K., Lamzin, V., and Ermler, U. (2001) On the mechanism of biological methane formation: Structural evidence for conformational changes in methyl-coenzyme M reductase upon substrate binding. J. Mol. Biol. 309, 315-330

31. Hinderberger, D., Ebner, S., Mayr, S., Jaun, B., Reiher, M., Goenrich, M., Thauer, R. K., and Harmer, J. (2008) Coordination and binding geometry of methyl-coenzyme M in the red1m state of methyl-coenzyme M reductase. J Biol Inorg Chem 13, 1275-1289

32. Lin, C.-Y., and Power, P. P. (2017) Complexes of Ni (I): A "rare" oxidation state of growing importance. Chemical Society Reviews 46, 5347-5399

33. Arendt, K. M., and Doyle, A. G. (2015) Dialkyl Ether Formation by Nickel-Catalyzed Cross-Coupling of Acetals and Aryl Iodides. Angewandte Chemie International Edition 54, 9876-9880 
34. Wongnate, T., and Ragsdale, S. W. (2015) The reaction mechanism of methyl-coenzyme $M$ reductase: how an enzyme enforces strict binding order. J Biol Chem 290, 9322-9334

35. Finazzo, C., Harmer, J., Jaun, B., Duin, E. C., Mahlert, F., Thauer, R. K., Van Doorslaer, S., and Schweiger, A. (2003) Characterization of the MCRred2 form of methyl-coenzyme M reductase: a pulse EPR and ENDOR study. J Biol Inorg Chem 8, 586-593

36. Mahlert, F., Grabarse, W., Kahnt, J., Thauer, R. K., and Duin, E. C. (2002) The nickel enzyme methyl-coenzyme $\mathrm{M}$ reductase from methanogenic archaea: in vitro interconversions among the EPR detectable MCR-red1 and MCR-red2 states. J Biol Inorg Chem 7, 101-112

37. Hinderberger, D., Ebner, S., Mayr, S., Jaun, B., Reiher, M., Goenrich, M., Thauer, R. K., and Harmer, J. (2008) Coordination and binding geometry of methyl-coenzyme M in the red $1 \mathrm{~m}$ state of methyl-coenzyme M reductase. Journal of Biological Inorganic Chemistry 13, 1275-1289

38. Chen, S.-L., Blomberg, M. R. A., and Siegbahn, P. E. M. (2012) How Is Methane Formed and Oxidized Reversibly When Catalyzed by Ni-Containing Methyl-Coenzyme M Reductase? Chemistry-a European Journal 18, 6309-6315

39. Chen, S.-L., Blomberg, M. R. A., and Siegbahn, P. E. M. (2012) How Is Methane Formed and Oxidized Reversibly When Catalyzed by Ni-Containing Methyl-Coenzyme M Reductase? Chemistry - A European Journal 18, 6309-6315

40. Gray, H. B., and Winkler, J. R. (2009) Electron Flow through Proteins. Chem Phys Lett 483, 1-9

41. Reece, S. Y., and Seyedsayamdost, M. R. (2017) Long-range proton-coupled electron transfer in the Escherichia coli class Ia ribonucleotide reductase. Essays Biochem 61, 281-292

42. Minnihan, E. C., Nocera, D. G., and Stubbe, J. (2013) Reversible, long-range radical transfer in E. coli class Ia ribonucleotide reductase. Acc Chem Res 46, 2524-2535

43. Dey, M., Li, X., Kunz, R. C., and Ragsdale, S. W. (2010) Detection of organometallic and radical intermediates in the catalytic mechanism of methyl-coenzyme $M$ reductase using the natural substrate methyl-coenzyme $\mathrm{M}$ and a coenzyme B substrate analogue. Biochemistry 49, 10902-10911

44. Symons, M. C. R. (1974) On the electron spin resonance detection of RS radicals in irradiated solids: radicals of type $\mathrm{RSSR}^{-}, \mathrm{RS}-\mathrm{SR}_{2}$, and $\mathrm{R}_{2} \mathrm{SSR}_{2}{ }^{+}$. J. Chem. Soc., Perkin Trans. 2, 1618-1620

45. Frey, P. A. (1997) Radicals in enzymatic reactions. Curr Opin Chem Biol 1, 347-356

46. Zehnder, A. J. B., and Wuhrmann, K. (1976) Titanium(Iii) Citrate as a Nontoxic Oxidation-Reduction Buffering System for Culture of Obligate Anaerobes. Science 194, $1165-1166$

47. Gunsalus, R. P., Romesser, J. A., and Wolfe, R. S. (1978) Preparation of coenzyme M analogues and their activity in the methyl coenzyme $\mathrm{M}$ reductase system of Methanobacterium thermoautotrophicum. Biochemistry 17, 2374-2377

48. Bobik, T. A., and Wolfe, R. S. (1988) Physiological importance of the heterodisulfide of coenzyme $\mathrm{M}$ and 7-mercaptoheptanoylthreonine phosphate in the reduction of carbon dioxide to methane in Methanobacterium. Proc Natl Acad Sci U S A 85, 60-63

49. Noll, K. M., Donnelly, M. I., and Wolfe, R. S. (1987) Synthesis of 7Mercaptoheptanoylthreonine Phosphate and Its Activity in the Methylcoenzyme-M Methylreductase System. Journal of Biological Chemistry 262, 513-515 
bioRxiv preprint doi: https://doi.org/10.1101/2021.01.25.428124; this version posted January 26, 2021. The copyright holder for this preprint (which was not certified by peer review) is the author/funder, who has granted bioRxiv a license to display the preprint in perpetuity. It is made available under aCC-BY-NC-ND 4.0 International license.

Substrate binding via nickel-sulfonate to methyl-SCoM reductase

50. Kunz, R. C., Horng, Y. C., and Ragsdale, S. W. (2006) Spectroscopic and kinetic studies of the reaction of bromopropanesulfonate with methyl-coenzyme M reductase. $J$ Biol Chem 281, 34663-34676

51. Becker, D. F., and Ragsdale, S. W. (1998) Activation of methyl-SCoM reductase to high specific activity after treatment of whole cells with sodium sulfide. Biochemistry 37 , 2639-2647

52. Tenderholt, A., Hedman, B., and Hodgson, K. O. (2007) PySpline: A Modern, CrossPlatform Program for the Processing of Raw Averaged XAS Edge and EXAFS Data. in $X$-ray Absorption Fine Structure - XAFS13 (B. Hedman, and Pianetta, P. eds.), American Institute of Physics, Stanford University

53. Mustre de Leon, J., Rehr, J. J., Zabinsky, S. I., and Albers, R. C. (1991) Ab initio curvedwave X-ray-absorption fine structure. Physical review. B, Condensed matter 44, 41464156

54. Rehr, J. J., Deleon, J. M., Zabinsky, S. I., and Albers, R. C. (1991) Theoretical X-Ray Absorption Fine-Structure Standards. Journal of the American Chemical Society 113, 5135-5140

55. Zabinsky, S. I., Rehr, J. J., Ankudinov, A., Albers, R. C., and Eller, M. J. (1995) Multiple-Scattering Calculations of X-Ray-Absorption Spectra. Physical Review B 52, 2995-3009

56. http://avogadro.openmolecules.net/. Avogadro: an open-source molecular builder and visualization tool.

57. George, G. N. (2000) EXAFSPAK and EDG-FIT, Stanford Synchrotron Radiation Laboratory, Stanford Linear Accelerator Center, Stanford, CA

58. Aprà, E., Bylaska, E. J., de Jong, W. A., Govind, N., Kowalski, K., Straatsma, T. P., Valiev, M., van Dam, H. J. J., Alexeev, Y., Anchell, J., Anisimov, V., Aquino, F. W., Atta-Fynn, R., Autschbach, J., Bauman, N. P., Becca, J. C., Bernholdt, D. E., BhaskaranNair, K., Bogatko, S., Borowski, P., Boschen, J., Brabec, J., Bruner, A., Cauët, E., Chen, Y., Chuev, G. N., Cramer, C. J., Daily, J., Deegan, M. J. O., Dunning, T. H., Dupuis, M., Dyall, K. G., Fann, G. I., Fischer, S. A., Fonari, A., Früchtl, H., Gagliardi, L., Garza, J., Gawande, N., Ghosh, S., Glaesemann, K., Götz, A. W., Hammond, J., Helms, V., Hermes, E. D., Hirao, K., Hirata, S., Jacquelin, M., Jensen, L., Johnson, B. G., Jónsson, H., Kendall, R. A., Klemm, M., Kobayashi, R., Konkov, V., Krishnamoorthy, S., Krishnan, M., Lin, Z., Lins, R. D., Littlefield, R. J., Logsdail, A. J., Lopata, K., Ma, W., Marenich, A. V., Martin del Campo, J., Mejia-Rodriguez, D., Moore, J. E., Mullin, J. M., Nakajima, T., Nascimento, D. R., Nichols, J. A., Nichols, P. J., Nieplocha, J., Otero-dela-Roza, A., Palmer, B., Panyala, A., Pirojsirikul, T., Peng, B., Peverati, R., Pittner, J., Pollack, L., Richard, R. M., Sadayappan, P., Schatz, G. C., Shelton, W. A., Silverstein, D. W., Smith, D. M. A., Soares, T. A., Song, D., Swart, M., Taylor, H. L., Thomas, G. S., Tipparaju, V., Truhlar, D. G., Tsemekhman, K., Van Voorhis, T., Vázquez-Mayagoitia, Á., Verma, P., Villa, O., Vishnu, A., Vogiatzis, K. D., Wang, D., Weare, J. H., Williamson, M. J., Windus, T. L., Woliński, K., Wong, A. T., Wu, Q., Yang, C., Yu, Q., Zacharias, M., Zhang, Z., Zhao, Y., and Harrison, R. J. (2020) NWChem: Past, present, and future. The Journal of Chemical Physics 152

59. Becke, A. D. (1993) Density-Functional Thermochemistry .3. The Role of Exact Exchange. J Chem Phys 98, 5648-5652 
60. Stephens, P. J., Devlin, F. J., Chabalowski, C. F., and Frisch, M. J. (1994) Ab-Initio Calculation of Vibrational Absorption and Circular-Dichroism Spectra Using DensityFunctional Force-Fields. J Phys Chem-Us 98, 11623-11627

61. Grimme, S., Antony, J., Ehrlich, S., and Krieg, H. (2010) A consistent and accurate ab initio parametrization of density functional dispersion correction (DFT-D) for the 94 elements $\mathrm{H}-\mathrm{Pu}$. The Journal of Chemical Physics 132

62. Frisch, M. J., Pople, J. A., and Binkley, J. S. (1984) Self-consistent molecular orbital methods 25. Supplementary functions for Gaussian basis sets. The Journal of Chemical Physics 80, 3265-3269

63. Hay, P. J., and Wadt, W. R. (1985) Ab initio effective core potentials for molecular calculations. Potentials for the transition metal atoms Sc to Hg. The Journal of Chemical Physics 82, 270-283

64. Bauernschmitt, R., Haser, M., Treutler, O., and Ahlrichs, R. (1997) Calculation of excitation energies within time-dependent density functional theory using auxiliary basis set expansions. Chemical Physics Letters 264, 573-578

65. Jamorski, C., Casida, M. E., and Salahub, D. R. (1996) Dynamic polarizabilities and excitation spectra from a molecular implementation of time-dependent density-functional response theory: N-2 as a case study. J Chem Phys 104, 5134-5147

66. Bauernschmitt, R., and Ahlrichs, R. (1996) Treatment of electronic excitations within the adiabatic approximation of time dependent density functional theory. Chemical Physics Letters 256, 454-464

67. Gift, A. D., Stewart, S. M., and Kwete Bokashanga, P. (2012) Experimental Determination of pKa Values by Use of NMR Chemical Shifts, Revisited. Journal of Chemical Education 89, 1458-1460 


\section{Substrate binding via nickel-sulfonate to methyl-SCoM reductase}

\section{FIGURES}

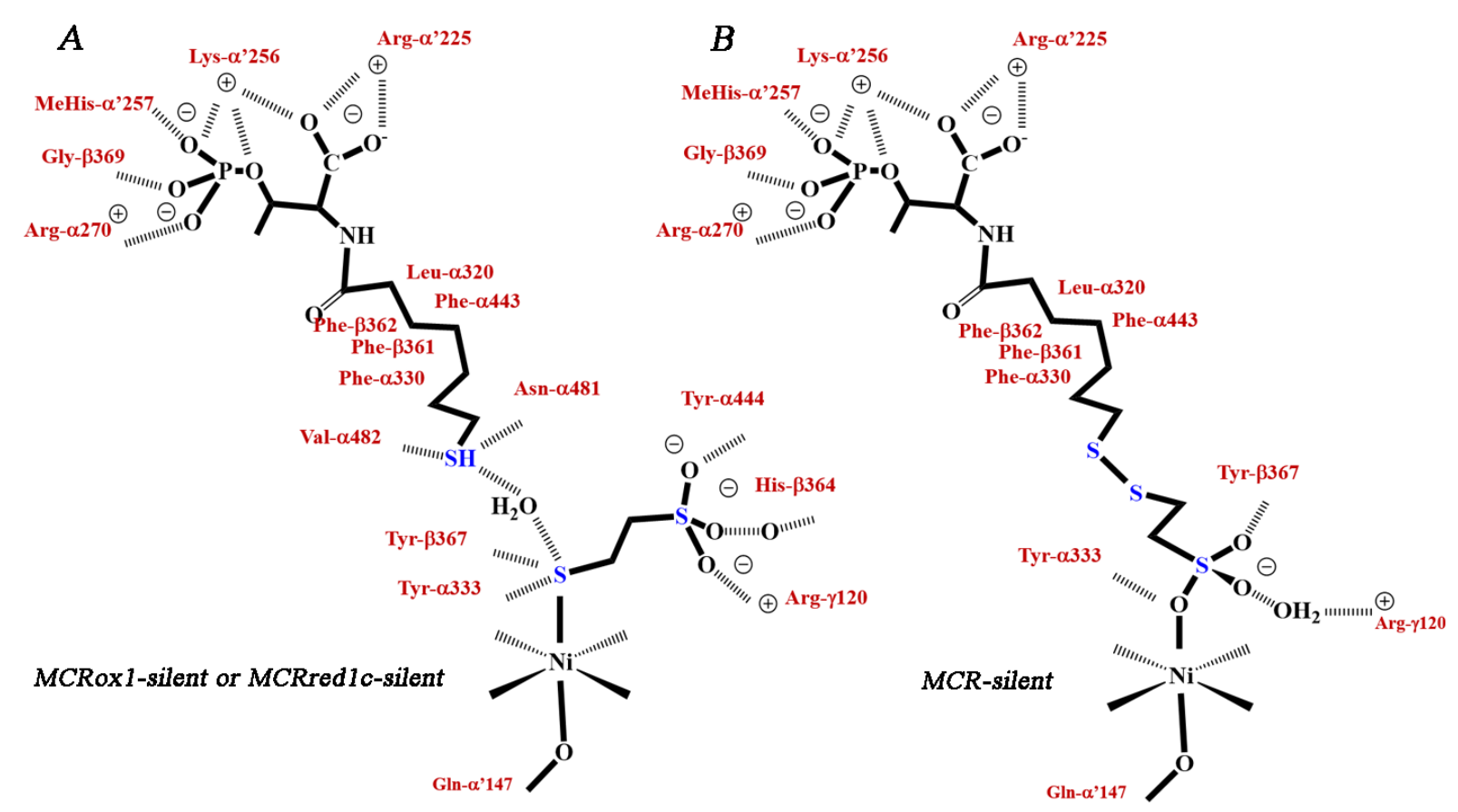

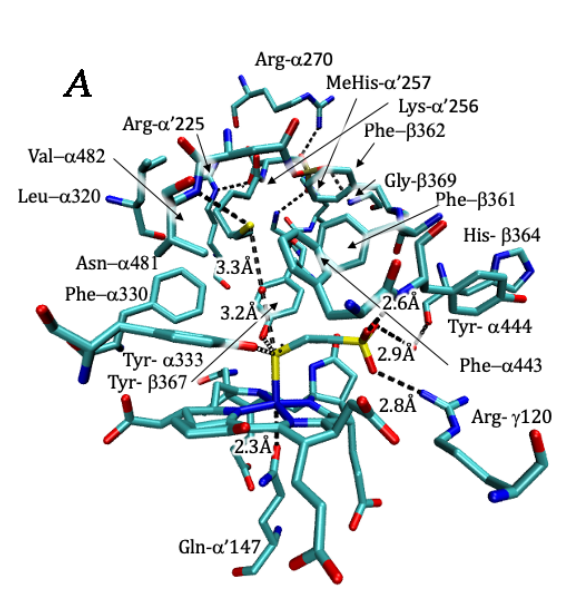

MCRox1-silent or MCRredlc-silent

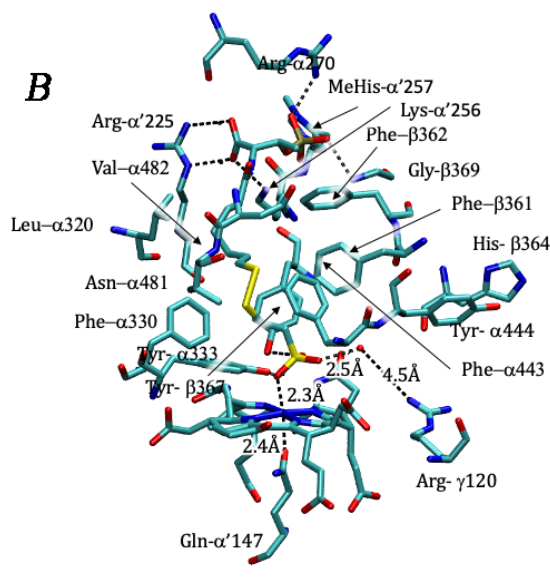

MCR-silent

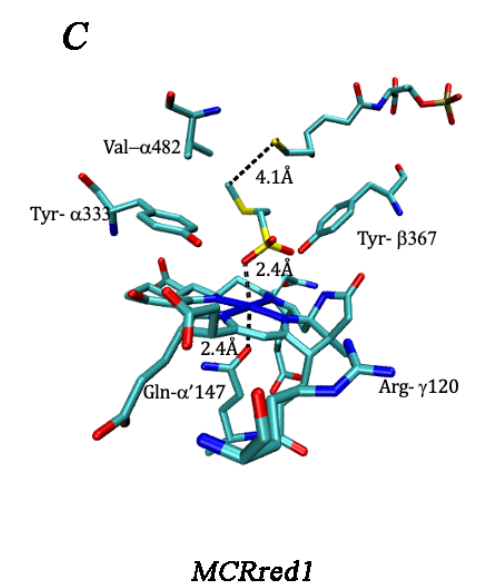

Figure 1. Representative interactions in the active site of MCR. Top. A: MCRox1-silent or MCRred1c-silent. B; MCR-silent. CoB part of the molecule in both A and B are stabilized at the top of channel by electrostatic interactions with phosphate and carboxylate residues. The methylene $\left[\left(\mathrm{CH}_{2}\right)_{6-}\right.$ $\mathrm{CO}$ s section of $\mathrm{CoB}$ interacts with hydrophobic residues of the protein. $\mathrm{H}$ - bonds to the $\mathrm{S}$ - of CoMSH in the reduced form (A) are replaced by H-bonds to the sulfonate-O- of the CoM moiety in CoMSSCoB (B). In A, Coenzyme $\mathrm{M}$ is anchored to the protein by the negatively charged sulfonate group, forming a salt bridge to the guanidinium group of Arg- $\gamma 120$, a hydrogen bond to Tyr- $\alpha 444$, and a hydrogen bond to a water molecule connected to the peptide oxygen of His- $\beta 364$. In B, one oxygen atom of the sulfonate is axially coordinated with the nickel and contacts the hydroxyl group of Tyr- $\alpha 333$. The second oxygen atom is hydrogen-bonded to the lactam ring of $\mathrm{F}_{430}$ (not shown) and to the hydroxyl group of Tyr- $\beta 367$ and the third to a water molecule located at the former binding site of the sulfonate in A (20). Structure details obtained from pdb1mro. Bottom. A. MCRox1-silent or MCRred1c-silent. B. MCR-silent. C. 
Substrate binding via nickel-sulfonate to methyl-SCoM reductase

MCRred1 with methyl-SCoM and CoBSH modeled into the active site showing the predicted distances between the S-methyl carbon and the HSCoB hydrogen atom to undergo abstraction. In figure $\mathrm{C}, \mathrm{F} 430$ and all residues except for methyl-SCoM and $\mathrm{HS}-\mathrm{CH}_{2}-\mathrm{CH}_{2}$ - tail of $\mathrm{HSCoB}$ are from pdb1hbm. The calculated QM model (Fig 10(3)) was overlapped with pdb1hm based on the subset of atoms fixed in the crystal structure position during the optimization, and all atoms except for the ones representing the substrates were removed. 


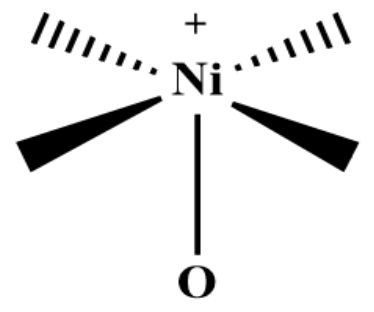

MCRred 1

MCRred1m

MCRred1c

5-coordinate $\mathrm{Ni}(\mathrm{I})$

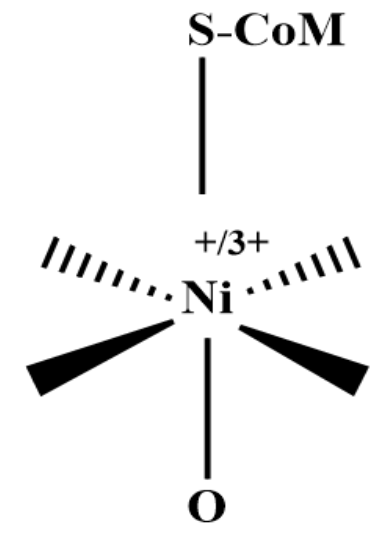

MCRox 1

6-coordinate $\mathrm{Ni}(\mathrm{I}) /(\mathrm{III})$

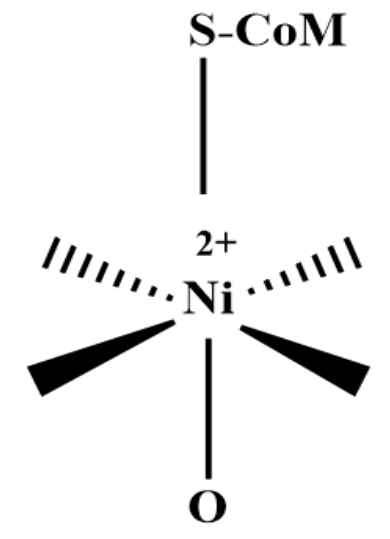

MCRox1-silent

MCRred1c-silent 6-coordinate $\mathrm{Ni}(\mathrm{II})$

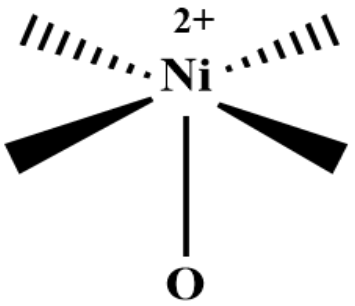

MCRred1-silent 5-coordinate $\mathrm{Ni}(\mathrm{II})$

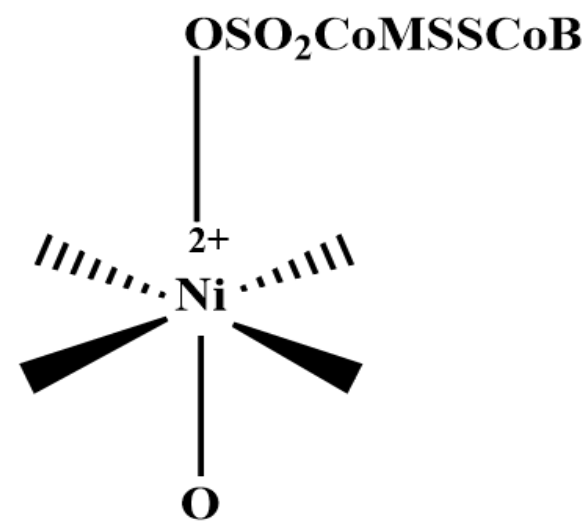

MCR-silent

6-coordinate $\mathrm{Ni}(\mathrm{II})$

Figure 2: Various states of MCR, with their observed oxidation states and coordination geometries. MCRred1m: MCRred1 with methyl-SCoM, MCRred1c: MCRred1 with coenzyme M, MCRox1: MCR in the ready state with $\mathrm{Ni}$ in the 1+/3+ oxidation, MCRred1-silent, MCRred1m-silent, MCRred1c-silent, MCRox1-silent are the corresponding $\mathrm{Ni}^{2+}$ states of the $\mathrm{Ni}^{1+}$ states, MCR-silent is the heterodisulfide (CoMSSCoB) bound state observed by X-ray crystallography. 
Substrate binding via nickel-sulfonate to methyl-SCoM reductase

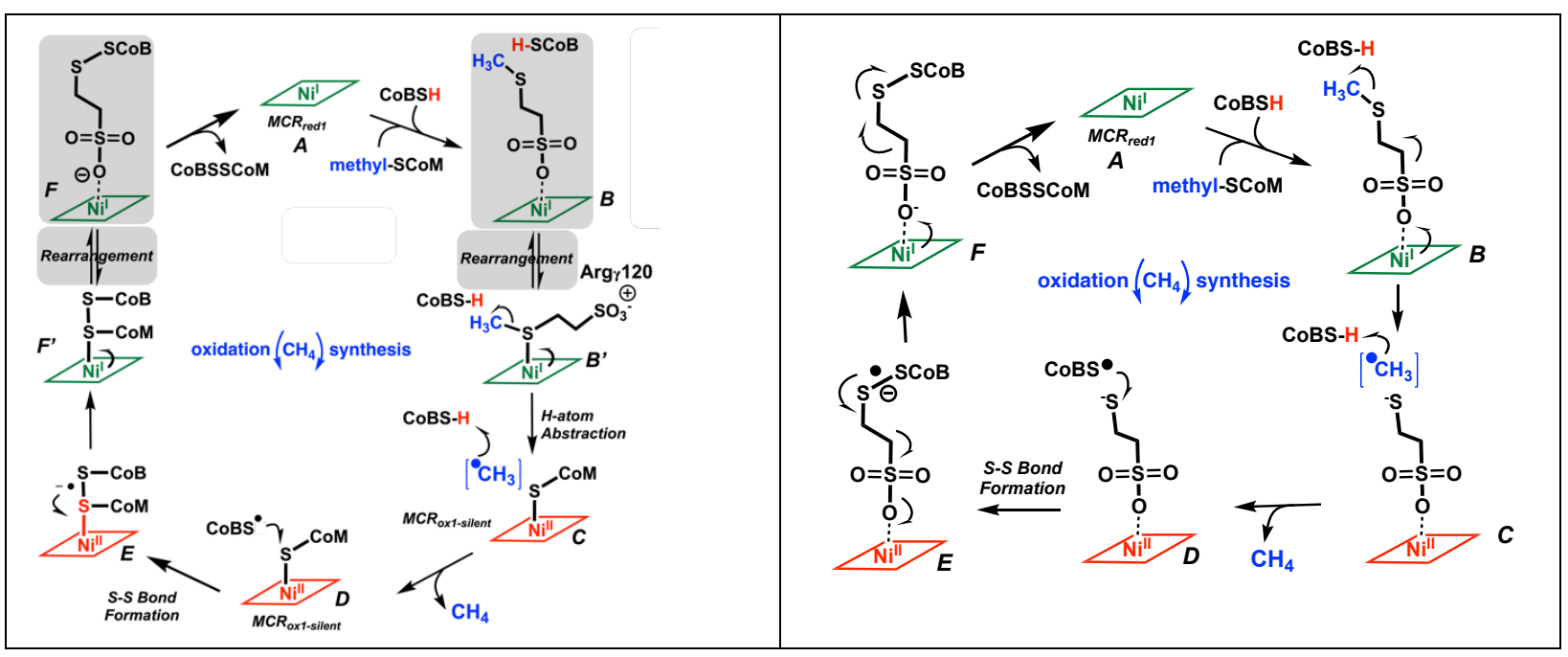

Figure 3. Contrasting mechanisms of activation of methane synthesis. (Left) Canonical mechanism through $\mathrm{Ni}(\mathrm{I})-\mathrm{S}$ species with direct $\mathrm{Ni} \rightarrow$ sulfur $\mathrm{ET}$. The shaded portion includes the sulfonate-bound substrates, which could rearrange to form Ni-thiol (B' or F') states proposed to be productive state in the canonical mechanism. (Right) Proposed mechanism of $\mathrm{CH}_{4}$ synthesis involving Ni-sulfonate species (B) as productive complexes and long-distance ET. See text for details. 

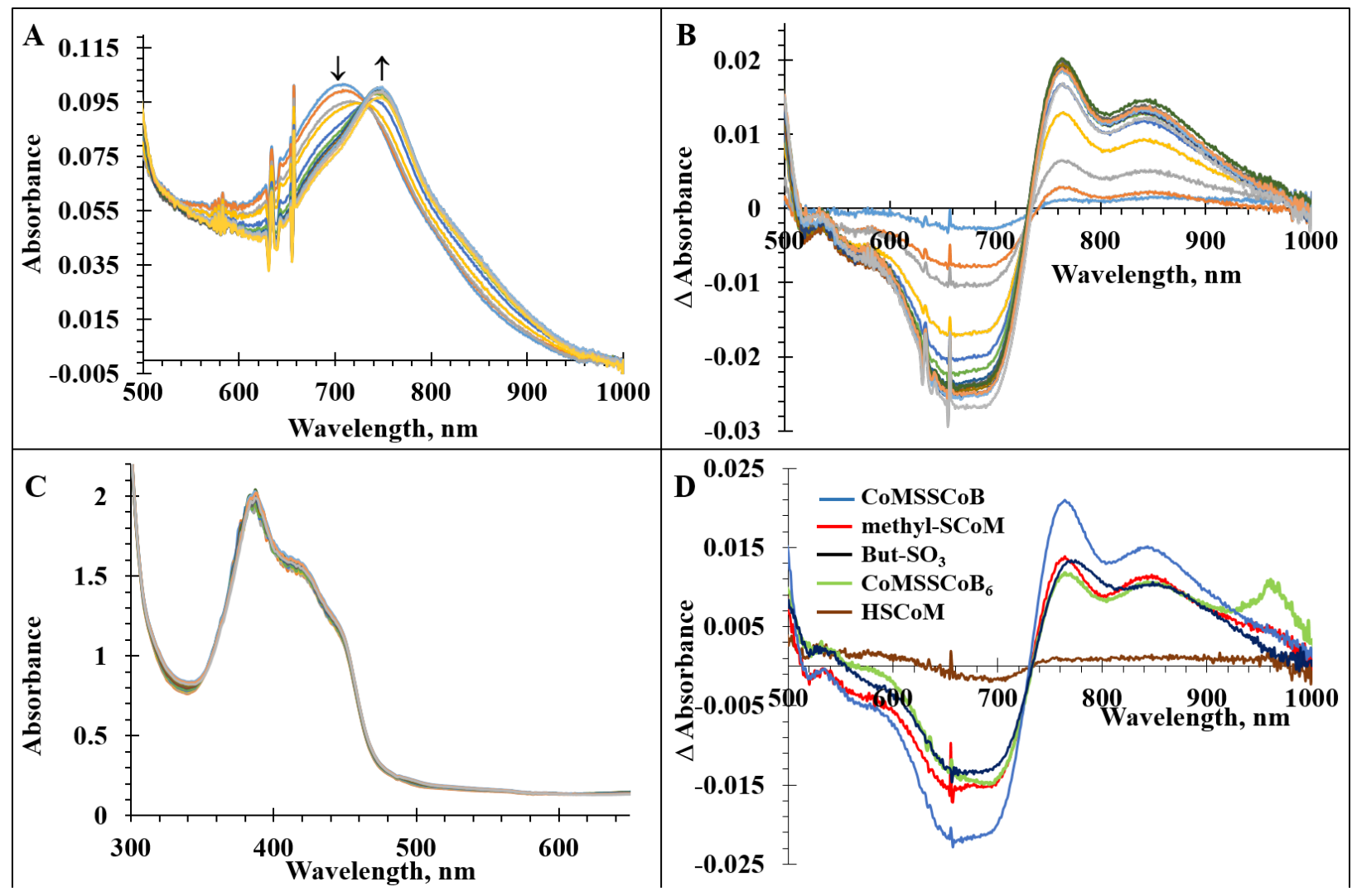

Figure 4: Binding substrates monitored by NIR spectroscopy. A: Red shift in $\lambda$ max from 700 $\mathrm{nm}$ to $750 \mathrm{~nm}$ of $\mathrm{Ni}(\mathrm{I})-\mathrm{MCR} r e d 1(50 \mu \mathrm{M})$ with increasing concentration of CoMSSCoB $(0-700 \mu \mathrm{M})$. B: Difference spectra of the spectra in panel A, highlighting the buried peaks at $768 \mathrm{~nm}$ and $850 \mathrm{~nm}$ on CoMSSCoB addition. C: The absorbance at $385 \mathrm{~nm}(\mathrm{Ni}(\mathrm{I}))$ and $420 \mathrm{~nm} \mathrm{Ni(II))} \mathrm{remains} \mathrm{unchanged} \mathrm{during}$ the addition of the substrate suggesting no redox reaction at the Ni(I) center. D: Comparative difference spectra for the addition of $500 \mu \mathrm{M}$ of CoMSH (green), Methyl-SCoM (red), CoMSSCoB (Blue) and $\mathrm{CoMSSCoB}_{6}$ (yellow) and But-SO 3 (black) each to MCRred1 $(50 \mu \mathrm{M})$. 

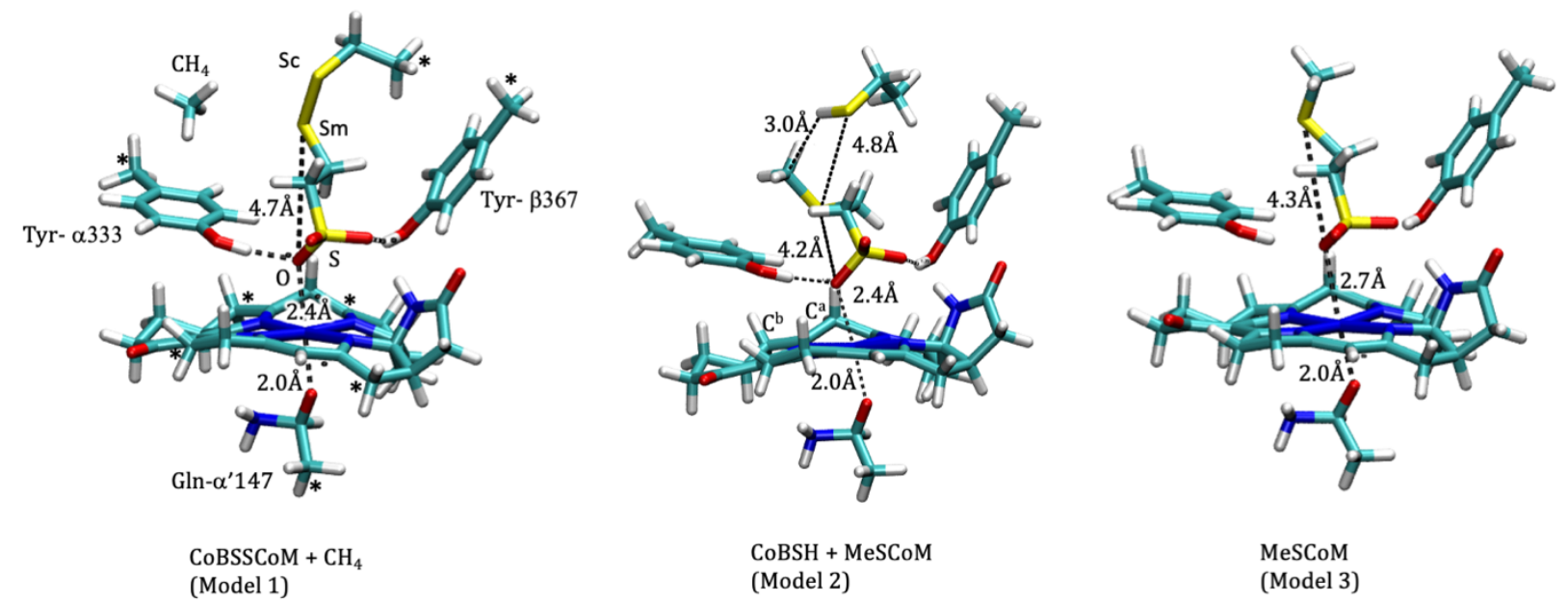

Figure 5. Structures optimized using DFT 1) Ni(I) binding CoMS-SCoB, where CoB is truncated after the second carbon from the $\mathrm{S}_{\mathrm{b}}, 2$ ) Ni(I) binding methyl-SCoM and 3) Ni(I) binding CoBSH and methylSCoM. All models were build starting from crystal structure 1HBM. Truncation points from the enzyme are annotated with asterisks and were fixed in place during the optimization. 
A

B

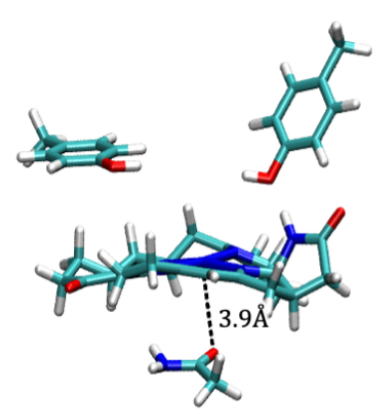

\begin{abstract}
B
\end{abstract}

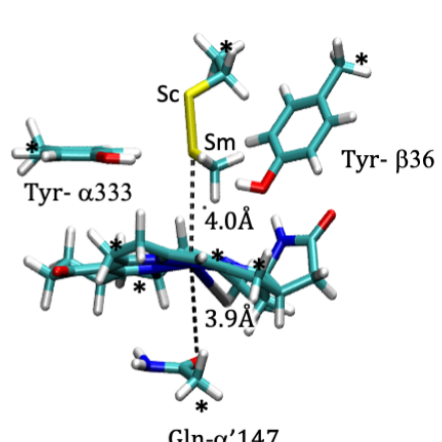

Gln- $\alpha^{\prime} 147$

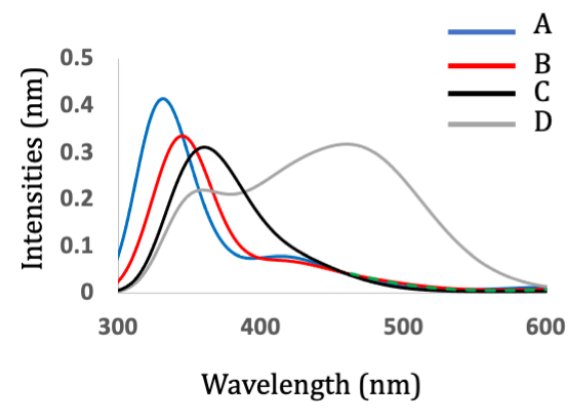

C

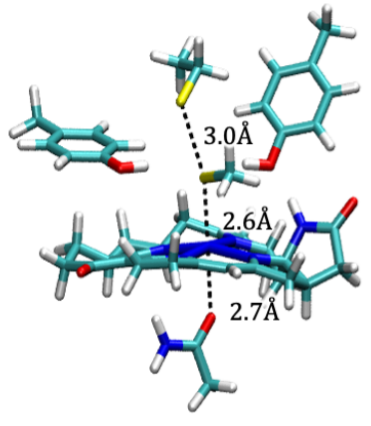

D

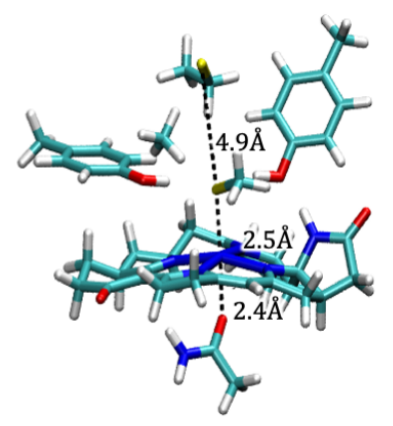

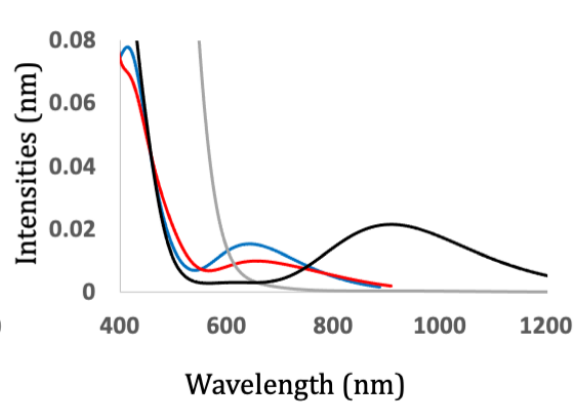

Fig. 6. Computational models of the canonical mechanism involving $\mathrm{Ni}-\mathrm{S}_{\mathrm{m}}$ coordination and TDDFT calculations of MCR UV-vis and NIR spectra. (B) and bond formation (C and D). All models were previously reported in Ref (38). Structures A and B are Ni(I) state, and structures C and D are Ni(II). (a) Major features of the spectra as captured by the TDDFT calculations for all models shown on the bottom panels and are able to qualitatively capture the shifts in the various structures (bottom, left panels). (b) shows that d-d transitions are captured for structures A (MCRred1) and B (MCRred1 + CoMSSCoB) at around $650 \mathrm{~nm}$ (bottom, right panel). 


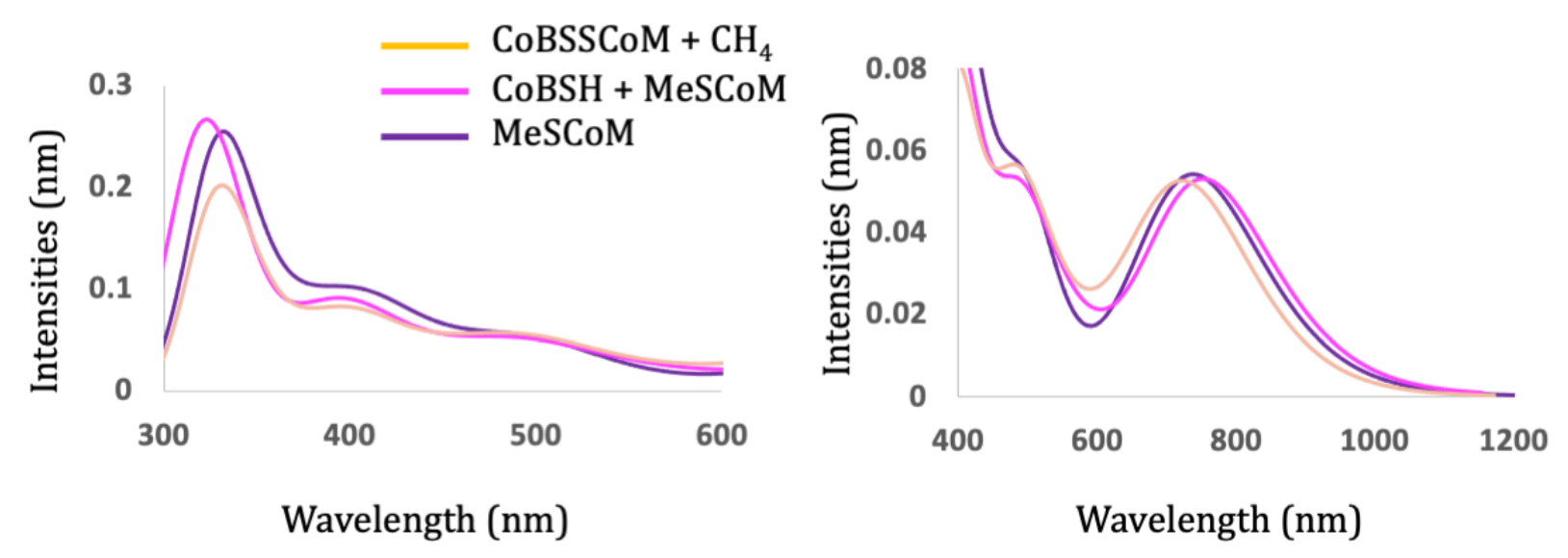

Fig. 7. TDDFT calculations of MCR UV-vis and NIR spectra. (a) Major features of the spectra as captured by the TDDFT calculations for the models shown in Fig. 5, are able to qualitatively capture the shifts in the various structures (left panels). (b) shows that $d-d$ transitions are captured for all three structures $\sim 600 \mathrm{~nm}$, and extend beyond 800 in the NIR region ( right panel). The more prominent peak at $\sim 740 \mathrm{~nm}$ captures $\boldsymbol{\pi}$ to $\boldsymbol{\pi}^{*}$ on $\mathrm{F}_{430}$. 

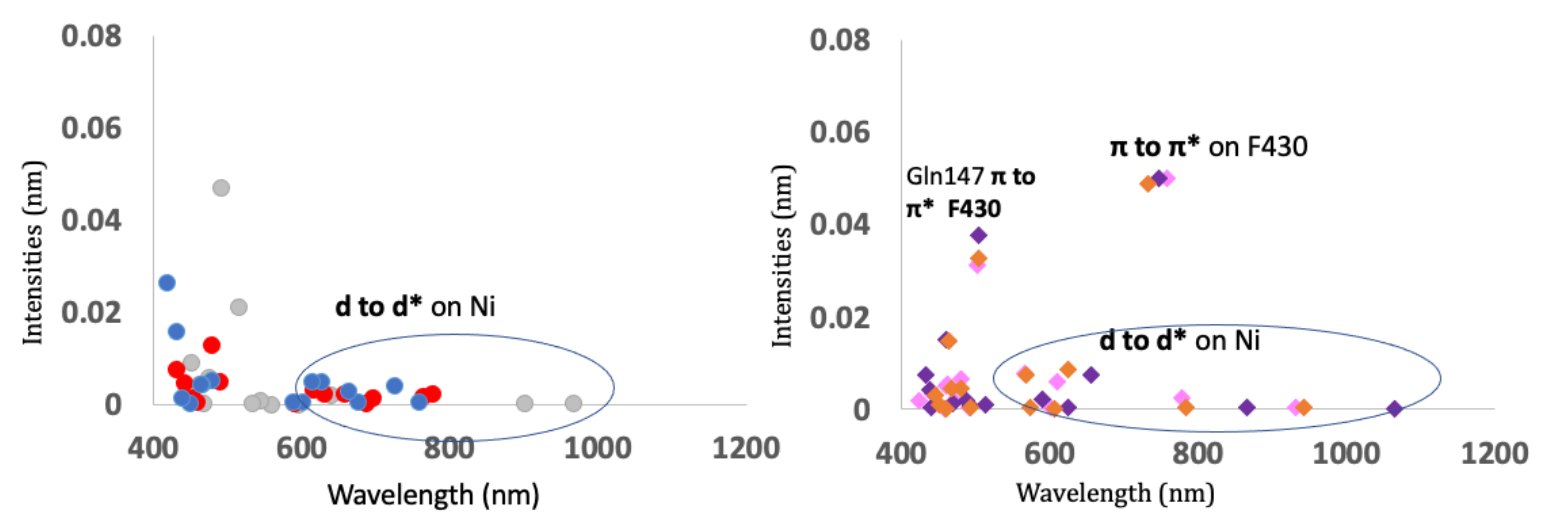

Fig. 8. Excitation from TDDFT used in reconstructing the spectra. The calculated transitions used to reproduce the spectra in the d-d region for all models shown in Fig. 5 (right panel) and Fig. 6 (left panel). 
A

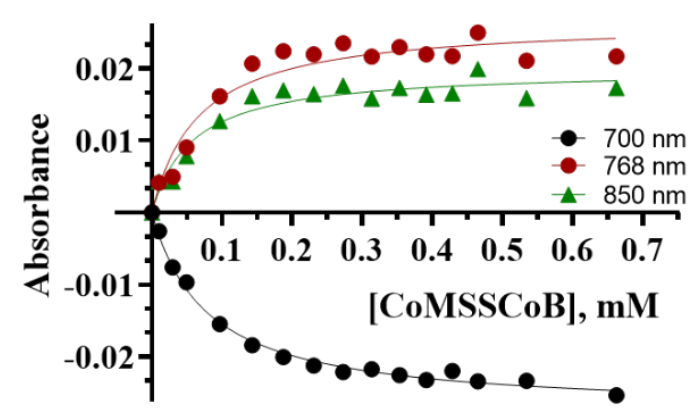

C

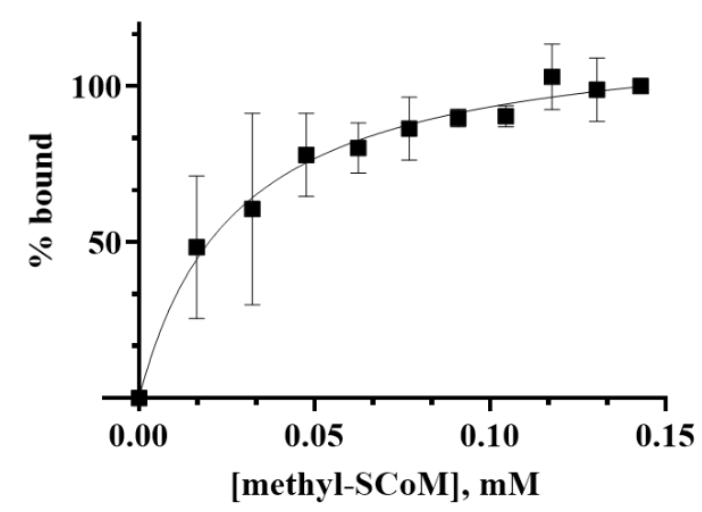

B
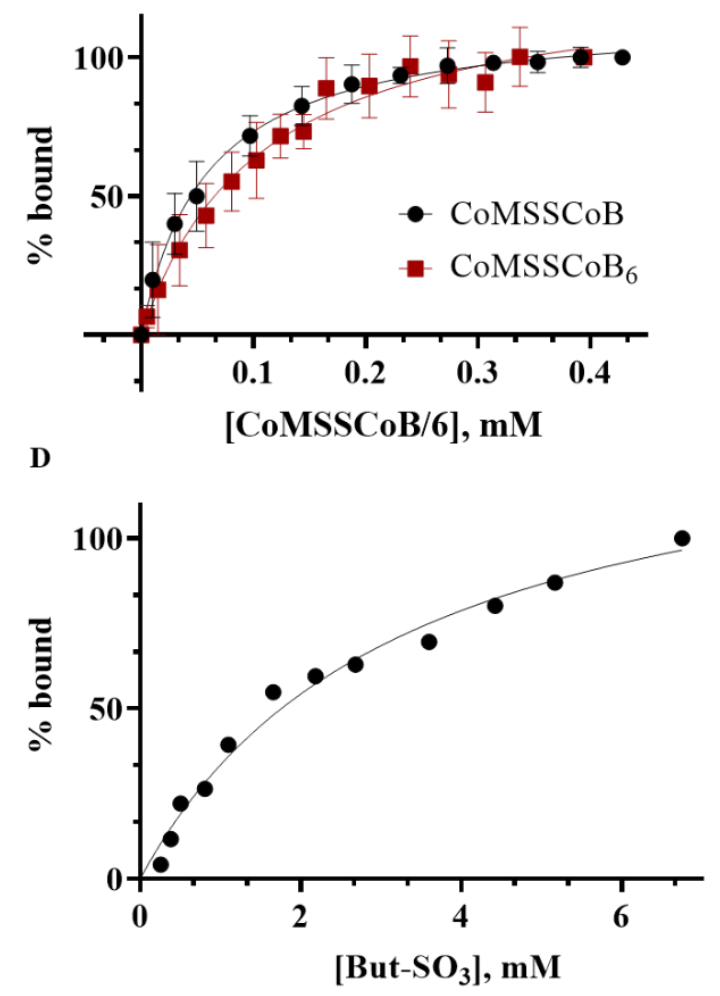

Figure 9: Determination of dissociation constants for MCR substrates and analogs based on NIR spectral changes. A: Plot of changes in absorbance at $700 \mathrm{~nm}$ (black), $768 \mathrm{~nm}$ (red), $850 \mathrm{~nm}$ (green) with increasing concentrations of CoMSSCoB. B: Plot of percent enzyme bound to substrate with addition of increasing concentrations of $\mathrm{CoMSSCoB}$ (black) and $\mathrm{CoMSSCoB}_{6}(\mathrm{red})$. The data was fit to a one site specific binding equation to obtain $\mathrm{K}_{\mathrm{d}}=57.4 \pm 5.4 \mu \mathrm{M}$ and $105.3 \pm 10.9 \mu \mathrm{M}$ for CoMSSCoB and $\mathrm{CoMSSCoB}_{6}$ respectively. $\mathrm{C}$ and D: One site specific binding isotherm for methyl-SCoM gives a $\mathrm{K}_{\mathrm{d}}=$ $27.53 \pm 7.6 \mu \mathrm{M}$ and $\mathrm{But}_{-} \mathrm{SO}_{3}$ gives a $\mathrm{K}_{\mathrm{d}}=3.3 \pm 0.6 \mathrm{mM}$, respectively. 
Substrate binding via nickel-sulfonate to methyl-SCoM reductase
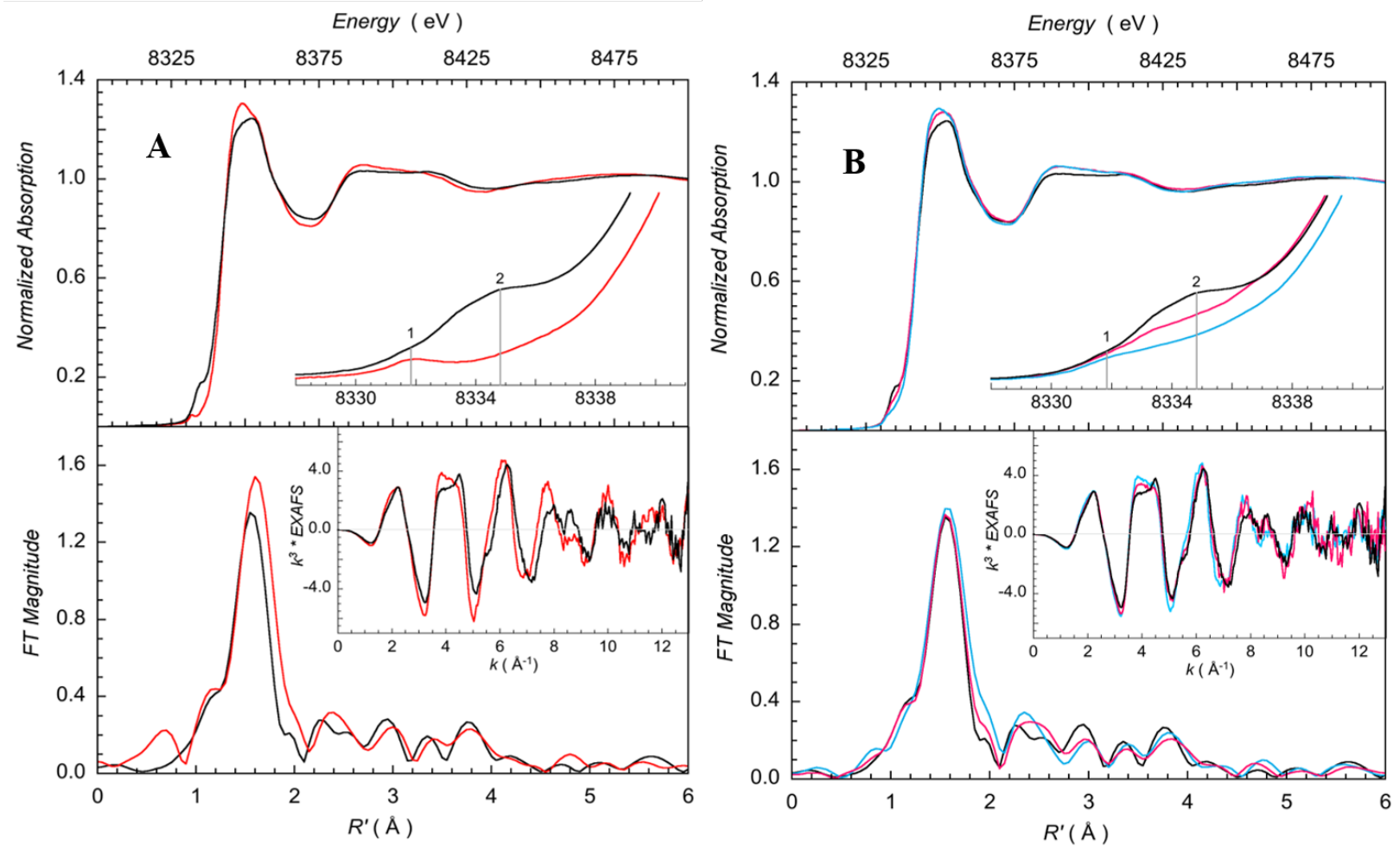

Figure 10. Ni K-edge XAS of MCR + CoBSSCoM. Top row: A comparison of the normalized Ni Kedge XAS data for (A) $\mathrm{MCR}_{\text {Red1 }}(-)$ and $\mathrm{MCR}_{\text {Red } 1 \text { Silent }}(-)$ and (B) $\mathrm{MCR}_{\text {Red } 1}(-), \mathrm{MCR}_{\text {Red1 }}+$ CoMSSCoB (-) and $\mathrm{MCR}_{\mathrm{Red} 1}+\mathrm{CoMSSCoB} 6(-)$. The inset in each plot shows the expanded pre-edge region. The markers at ' $\sim 8332 \mathrm{eV}$ ' and ' $\sim 8334.5 \mathrm{eV}$ ' represent the $1 \mathrm{~s} \rightarrow 3 \mathrm{~d}$ transition and the backbonding transition involving interactions between the F430 ring and the Ni center, respectively. Bottom row: A comparison of the Ni K-edge EXAFS data (inset) and their corresponding Fourier Transforms. 
Substrate binding via nickel-sulfonate to methyl-SCoM reductase
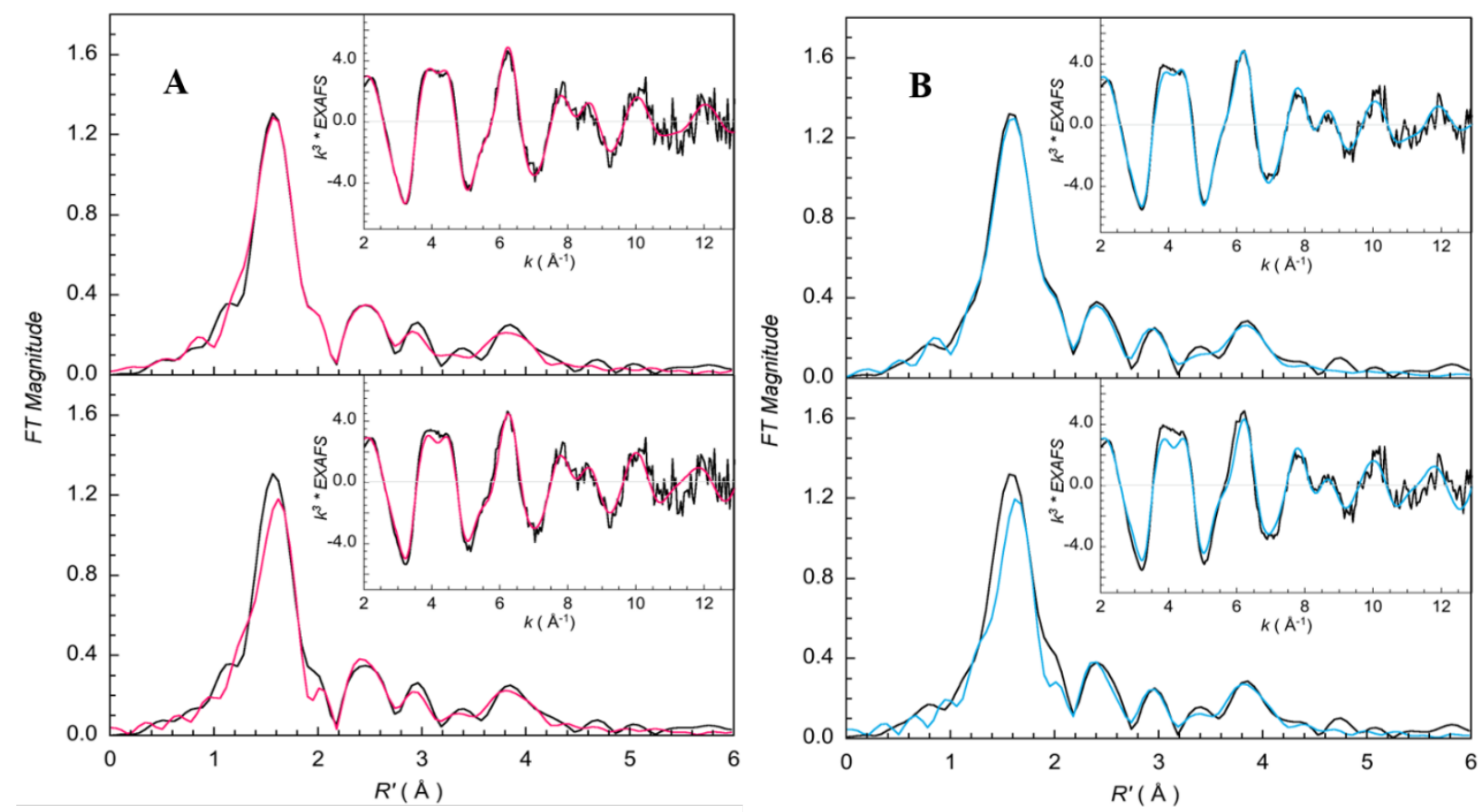

Figure 11. FEFF best fits Ni K-edge EXAFS data (inset) and corresponding Fourier Transforms. The (top) and (bottom) figures represent, respectively, fits with and without a longer Ni-O component in the first shell coordination sphere (see Table 3$)$. A. MCRred1 + $\operatorname{CoMSSCoB}_{6}$. Data (-), Fit (-). B. MCRred1 + CoMSSCoB Data (-), Fit (-) 

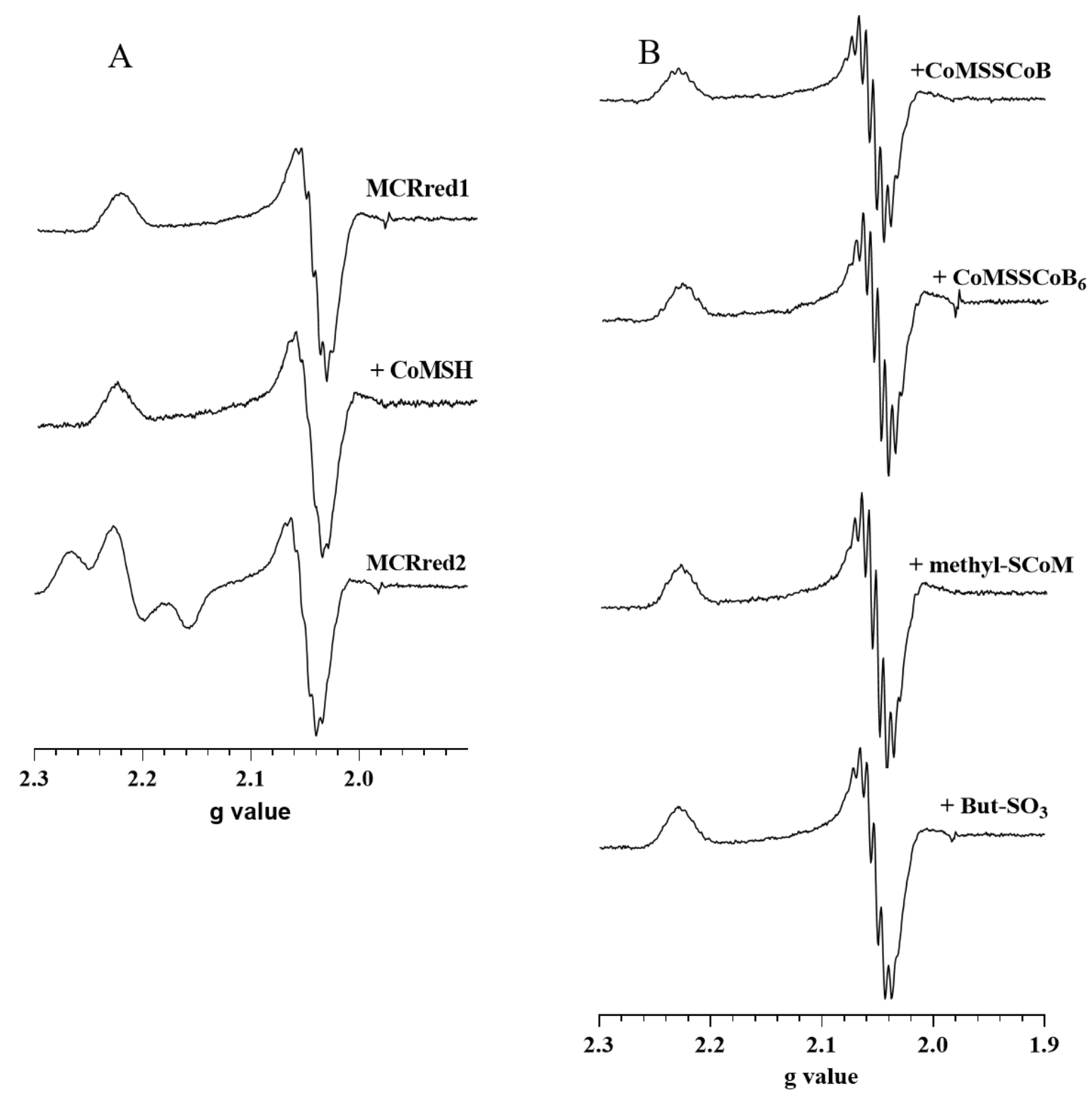

Figure 12. EPR spectra of MCRred1 with substrates A. MCRred1, MCRred1+ CoMSH, MCRred2 (MCRred1 + COMSH + HSCoB). B. (top to bottom) MCRred1 + CoMSSCoB; CoMSSCoB6; methyl$\mathrm{SCoM}$; But-SO $\mathrm{S}_{3}$ Typical EPR signals at 2.2201 and 2.0510 were seen. As shown earlier (36), the superhyperfine features undergo sharpening in the presence of methyl-SCoM but not with CoMSH. The sharpening also is observed with addition of $\mathrm{CoMSSCoB}, \mathrm{CoMSSCoB}_{6}$ and $\mathrm{But}_{-} \mathrm{SO}_{3}$ suggesting that they bind similar to methyl-SCoM binding to MCR. However, CoMSH binds differently. 


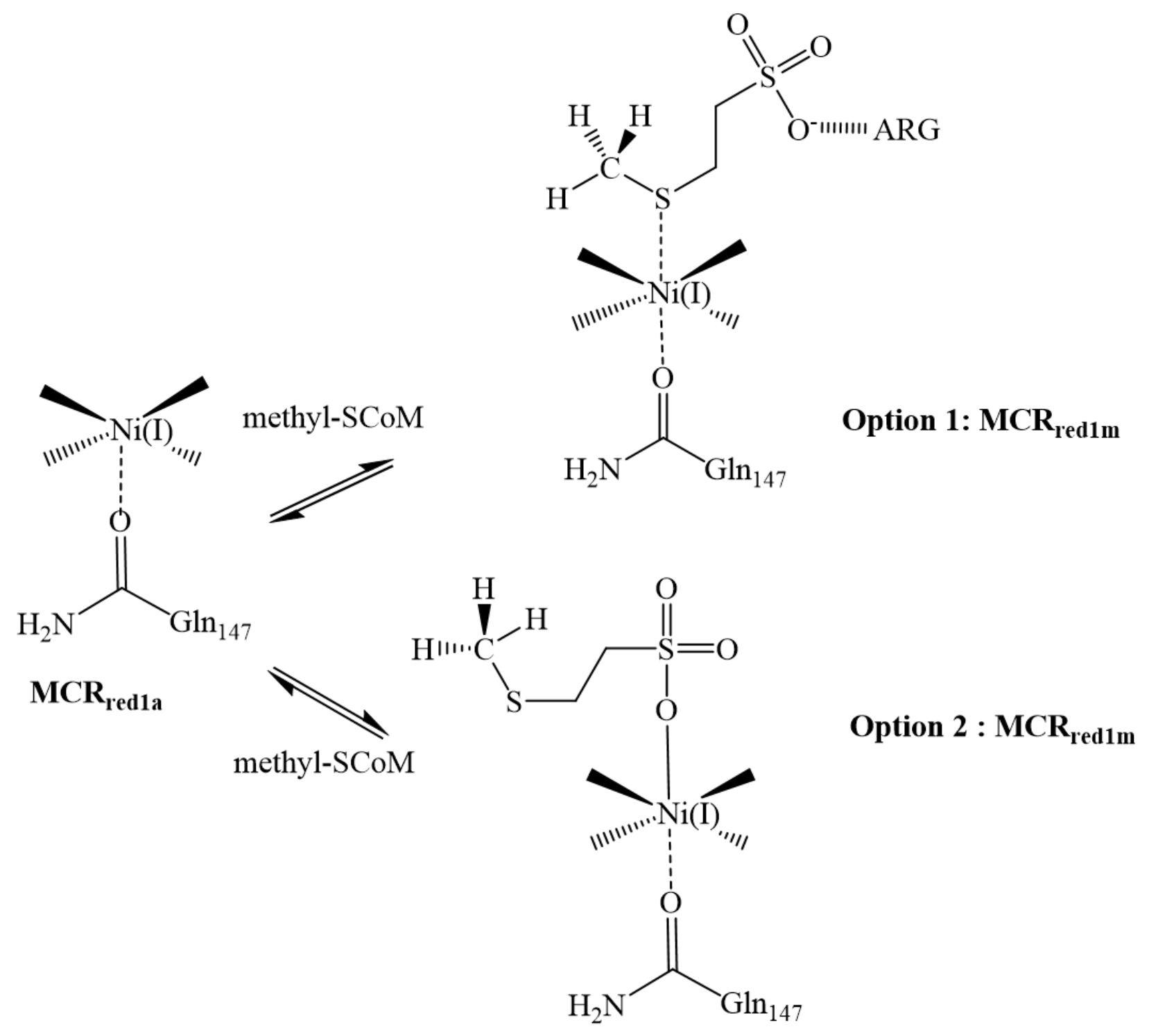

Figure 13: Proposed alternative binding mode for methyl-SCoM to MCR red1. Option 1 highlights the current mode of binding widely accepted as being through the $-\mathrm{S}$ of the thioether. Option 2 is our proposed binding mode as seen by NIR spectroscopy for binding of a sulfonate $-\mathrm{O}^{-}$to $\mathrm{Ni}(\mathrm{I})$. 
Table 1. Characteristic bond distances for the crystal structure and the three models in Figure 5 calculated using gas phase DFT approach

\begin{tabular}{|l|l|l|l|l|}
\hline Bond distance $(\AA)$ & $1 \mathrm{hbm}$ & CoMSSCoB $+\mathrm{CH}_{4}$ & $\begin{array}{l}\text { CoBSH-methyl- } \\
\text { SCoM }\end{array}$ & methyl-SCoM \\
\hline $\mathrm{Ni}-\mathrm{O}\left(\mathrm{Gln}_{147}\right)$ & 2.35 & 2.03 & 2.03 & 2.04 \\
\hline $\mathrm{Ni}-\mathrm{O}\left(\mathrm{SO}_{3}{ }^{-}\right)$ & 2.29 & 2.41 & 2.41 & 2.71 \\
\hline $\left.\mathrm{Ni} \mathrm{S}_{\left(\mathrm{SO}_{3}\right.}^{-}\right)$ & 3.29 & 3.42 & 3.45 & 3.62 \\
\hline $\mathrm{Ni}-\mathrm{S}_{\mathrm{m}}$ & 6.71 & 7.04 & 6.09 & 6.98 \\
\hline $\mathrm{Ni}-\mathrm{S}_{\mathrm{c}}$ & 8.46 & 8.47 & 8.48 & $\mathrm{n} / \mathrm{a}$ \\
\hline $\mathrm{C}(\mathrm{Me})-\mathrm{S}_{\mathrm{c}}$ & $\mathrm{n} / \mathrm{a}$ & 4.41 & 3.72 & $\mathrm{n} / \mathrm{a}$ \\
\hline
\end{tabular}

${ }^{*} \mathrm{~S}_{\mathrm{m}}$, thioether sulfur from methyl-SCoM; $\mathrm{S}_{\mathrm{c}}$, thiol sulfur from CoM. See Fig. 5.

Table 2. pKas of ionizable groups of the susbtrates as measured by $\mathrm{pH}$ titrations and NMR

A.

\begin{tabular}{|c|c|c|c|c|c|}
\hline \multicolumn{6}{|c|}{$\mathrm{pH}$ Titrations - $\mathrm{pKas}$} \\
\hline Substrate & $-\mathrm{SO}_{3} \mathrm{H}$ & $\mathrm{OPO}(\mathrm{OH})(\mathrm{OH})$ & $-\mathrm{COOH}$ & $\mathrm{OPO}(\mathrm{OH}) \mathrm{O}-$ & $-\mathrm{SH}$ \\
\hline CoMSH & 1.9 & & & & 9.4 \\
\hline Methyl-SCoM & 2.4 & & & & \\
\hline CoMSSCoB & & 1.8 & 4.2 & 7.3 & \\
\hline CoMSSCoB $_{6}$ & & 2.4 & 4.4 & & 9.1 \\
\hline
\end{tabular}

B.

\begin{tabular}{|c|c|c|c|c|c|}
\hline & & ${ }^{31} \mathrm{P}-\mathrm{NMR}$ & \multicolumn{3}{|c|}{${ }^{1} \mathrm{H}-\mathrm{NMR}$} \\
\hline \multirow{4}{*}{ CoMSSCoB } & & $\mathrm{pKa}$ & $\mathrm{pKa}\left(\mathrm{g}-{ }^{1} \mathrm{H}\right)$ & $\mathrm{pKa}\left(\mathrm{h}-{ }^{1} \mathrm{H}\right)$ & $\mathrm{pKa}\left(\mathrm{k}-{ }^{1} \mathrm{H}\right)$ \\
\cline { 2 - 6 } & $\mathrm{OPO}(\mathrm{OH})(\mathrm{OH})$ & 2.4 & & & $<1.25$ \\
\cline { 2 - 6 } & $\mathrm{OPO}(\mathrm{OH}) \mathrm{O}-$ & 6.6 & 6.2 & 6.8 & \\
\cline { 2 - 6 } & $-\mathrm{COOH}$ & & 4.3 & & \\
\hline \multirow{5}{*}{$\mathrm{CoBSH}$} & $\mathrm{OPO}(\mathrm{OH})(\mathrm{OH})$ & 4.8 & & & \\
\cline { 2 - 6 } & $\mathrm{OPO}(\mathrm{OH}) \mathrm{O}-$ & 6.6 & 6.4 & 7.2 & \\
\cline { 2 - 6 } & $-\mathrm{COOH}$ & & 4.1 & & \\
\hline
\end{tabular}


Table 3. Bond distances from XAS.

\begin{tabular}{|c|c|c|c|c|}
\hline & $\begin{array}{l}\text { Ni-N/O } \\
\text { (penta- } \\
\text { coordir }\end{array}$ & & \begin{tabular}{|l}
$\mathrm{Ni}-\mathrm{N} / \mathrm{O} \AA$ \\
(sixth ligand)
\end{tabular} & $\begin{array}{l}\text { Ni-S } \AA \\
\text { (sixth ligand) from } \\
\text { MCR red1 silent }\end{array}$ \\
\hline MCRred1 & $\begin{array}{r}2.03(4) \\
(1)\end{array}$ & $\begin{array}{l}\text { N ring } \\
\text { O Gln }\end{array}$ & & $2.39(0.3)-\mathrm{SHCoM}$ \\
\hline $\begin{array}{l}\text { MCRred1 + } \\
\text { CoMS-SCoB }\end{array}$ & $\begin{array}{r}2.04(4) \\
(1)\end{array}$ & $\begin{array}{l}\text { N ring } \\
\text { O Gln }\end{array}$ & $2.16(0.7) \quad-\mathrm{O}-\mathrm{SO}_{2} \mathrm{R}$ & $2.39(0.3)-\mathrm{SHCoM}$ \\
\hline $\begin{array}{l}\text { MCRred1 + } \\
\text { CoMS-SCoB }_{6}\end{array}$ & $\begin{array}{r}2.03(4) \\
(1)\end{array}$ & $\begin{array}{l}\text { N ring } \\
\text { O Gln }\end{array}$ & $2.16(0.7) \quad-\mathrm{O}-\mathrm{SO}_{2} \mathrm{R}$ & $2.39(0.3)-\mathrm{SHCoM}$ \\
\hline MCRred1c-silent & $\begin{array}{l}2.08(4) \\
2.20(1)\end{array}$ & $\begin{array}{l}\text { N ring } \\
\text { O Gln }\end{array}$ & & $2.42(1)-\mathrm{SHCoM}$ \\
\hline $\begin{array}{l}\text { MCRred1 + } \\
\text { CoMSH + HSCoB } \\
\text { (partial formation of } \\
\text { MCRred2) }\end{array}$ & $\begin{array}{r}2.05(4) \\
(1)\end{array}$ & $\begin{array}{l}\text { N ring } \\
\text { O Gln }\end{array}$ & $2.18(0.3)$ & $2.45(0.7)$ * \\
\hline
\end{tabular}

* XAS is unable to distinguish between MCRred1c-silent and MCRred2, Ni-S interaction.

All MCRred1 data were corrected for the presence of a 30\% MCRred1c-silent as a contaminant.

Table 4. Electron spins calculated using Mulliken population analysis at the Ni and select carbons in $\mathrm{F}_{430}$ as shown in Figure 5.

\begin{tabular}{|l|l|l|l|}
\hline Spin & CoBSSCoM $+\mathrm{CH}_{4}$ & $\begin{array}{l}\text { HSCoB-methyl- } \\
\text { SCoM }\end{array}$ & $\begin{array}{l}\text { methyl- } \\
\text { SCoM }\end{array}$ \\
\hline $\mathrm{Ni}$ & 1.6 & 1.6 & 1.6 \\
\hline $\mathrm{C}^{\mathrm{a}}$ & -0.56 & -0.56 & -0.59 \\
\hline $\mathrm{C}^{\mathrm{b}}$ & -0.39 & -0.39 & -0.35 \\
\hline
\end{tabular}

